\title{
A process variability control chart
}

\author{
Muhammad Riaz • Ronald J. M. M. Does
}

Received: 19 April 2007 / Accepted: 6 May 2008 / Published online: 24 May 2008

(C) The Author(s) 2008

\begin{abstract}
In this study a Shewhart type control chart namely the $V_{t}$ chart, is proposed for improved monitoring of the process variability of a quality characteristic of interest $Y$. The proposed control chart is based on the ratio type estimator of the variance using a single auxiliary variable $X$. It is assumed that $(Y, X)$ follows a bivariate normal distribution. The design structure of the $V_{t}$ chart is developed for Phase-I quality control and its comparison is made with those of the $S^{2}$ chart (a well-known Shewhart control chart) and the $V_{r}$ chart (a Shewhart type control chart proposed by Riaz (Comput Stat, 2008a) used for the same purpose. It is observed that the proposed $V_{t}$ chart outperforms the $S^{2}$ and $V_{r}$ charts, in terms of discriminatory power, for detecting moderate to large shifts in the process variability. It is observed that the performance of the $V_{t}$ chart keeps improving with an increase in $\left|\rho_{y x}\right|$, where $\rho_{y x}$ is the correlation between $Y$ and $X$.
\end{abstract}

Keywords Auxiliary information - Normality · Power curves - Simulations . $S^{2}$ charts $\cdot V_{t}$ chart $\cdot V_{r}$ chart

\section{Introduction}

The monitoring of any process output demands an early detection of shifts in the process parameters. The shift may be in the process variability or the process mean

M. Riaz (ه)

Department of Statistics, Quaid-i-Azam University, Islamabad, Pakistan e-mail: riaz76qau@yahoo.com

R. J. M. M. Does

Institute for Business and Industrial Statistics, University of Amsterdam, Amsterdam, The Netherlands

e-mail: rjmmdoes@science.uva.nl 
level or both. The variability of any process is controlled first, followed by controlling of the mean level. In 1920s Walter A. Shewhart introduced the idea of control charts to monitor any process for variability or mean level. The commonly used control charts for monitoring the process variability include the $R$ chart, $S$ chart, and $S^{2}$ chart and for the process mean level include the $\bar{X}$ chart, median chart, trimmed mean chart, and mid-range chart.

Following the pioneering work of Walter A. Shewhart, researchers have developed a variety of control charts to monitor the parameters of any process using different classifications and different approaches. Farnum (1994) classified two basic types of control: threshold control and deviation control. Threshold control is concerned with detecting large shifts while deviation control is concerned with detecting small shifts in process parameters. The Shewhart type control charts are regarded as threshold control charts while non-Shewhart control charts (e.g., CUSUM and EWMA charts) are regarded as deviation control charts. There are different approaches which have been used to improve the efficiency of the control charts in detecting changes in the process parameters: for example, Battaglia (1993) used a regression based approach, Chun (2000) used a nonparametric control charting approach, Muttlak and Al-Sabah (2001) used a ranked sampling approach, Reynolds and Arnold (2001) used a variable sample size approach, Jones et al. (2004) used a CUSUM approach, Knoth (2005) used an EWMA approach, Chen and Huang (2005) used a synthetic control charting approach, He and Grigoryan (2006) used a double sampling approach, Muhammad and Riaz (2006) used a probability weighted moments based approach, Riaz and Saghir (2007) used a gini mean difference based approach, and Riaz (2008a,b) used an auxiliary information based approach.

The idea of using information on some auxiliary variable(s) along with the study variable(s) has been widely used in different areas of statistical analysis for the sake of gain in efficiency. The information on the relationship between the study and auxiliary variables helps improving the precision with which the parameters are estimated. According to Singh and Mangat (1996) "the prior information on an auxiliary variable can be used to enhance the precision of an estimator". There is a wide variety of literature available on using such auxiliary information to achieve higher efficiency. To refer but a few of these: Olkin (1958), Rao and Mudholkar (1967), Adhvaryu (1975), Isaki (1983), Naik and Gupta (1991), Magnus (2002), and Singh et al. (2004).

In the quality control literature, the idea of exploiting correlation of the quality characteristic(s) of interest with some other associated quality characteristic(s) of interest had been used by different researches. The cause-selecting and regression adjusted charts are very commonly used methods of capitalizing on the correlation between the study characteristic(s) and the auxiliary characteristic(s) for the sake of improved process monitoring, for example, see Mandel (1969), Zhang (1984, 1985), Hawkins (1991, 1993), Wade and Woodall (1993), and Shu et al. (2005).

Riaz (2008a,b) considered the information of an auxiliary characteristic $X$ for improved monitoring of the variance and the mean respectively of a quality characteristic of interest $Y$. Riaz (2008a) proposed a process variance chart (namely the $V_{r}$ chart) and claimed its superiority over the well known $S^{2}$ chart whereas Riaz (2008b) proposed a process mean chart (namely the $M_{r}$ chart) and claimed its superiority over the well known $\bar{X}$ chart, the cause-selecting and regression adjusted control charts. 
The $V_{r}$ and $M_{r}$ charts exploit the correlation of the auxiliary characteristic(s) with the study characteristic on the regression pattern for improved monitoring of the process variability and location parameters.

In this study, the information about an auxiliary characteristic $X$ is introduced for improved monitoring of process variability of a quality characteristic of interest $Y$, following Riaz (2008a). Assuming bivariate normality of $(Y, X)$ a new Shewhart type process variability control chart namely, the $V_{t}$ chart (a threshold control chart) is proposed which is based on a ratio type estimator of variance. The focus of this proposal would be Phase-I quality control. The ratio type estimator for variance of $Y$ using a single auxiliary variable $X$, is defined for a bivariate random sample $\left(y_{1}, x_{1}\right),\left(y_{2}, x_{2}\right), \ldots,\left(y_{n}, x_{n}\right)$ of size $n$ as (see Garcia and Cebrian 1996):

$$
V_{t}=s_{y}^{2}\left(\sigma_{x}^{2} / s_{x}^{2}\right)^{\rho_{y x}^{2}}
$$

where $s_{y}^{2}$ is the sample variance of $Y, s_{x}^{2}$ is the sample variance of $X, \sigma_{x}^{2}$ is the population variance of $X$ (assumed to be known) and $\rho_{y x}$ is the correlation (linear relationship) between $Y$ and $X$ ("In many practical situations we have information about the correlations between $X$ and $Y$ " see Garcia and Cebrian 1996).

The possibilities regarding the nature of an auxiliary characteristic $X$ may include: (i) $X$ is also a property that would be monitored (see Alt 1985), for example, Consider a polymer that has specifications on the density $Y$ and the tensile strength $X$; (ii) $X$ is a crude but simple to obtain measurement on the process (see Singh and Mangat 1996), for example, Consider a bottling operation where the important property is the net weight $Y$, but it is easy to record the filling speed $X$; (iii) $X$ is an early measurement in the process (see Shu et al. 2005), for example, Consider a polishing process where $X$ could be the time required to remove the large burrs on the product (an early step) and $Y$ is the finished thickness.

Hawkins (1993) concludes in his paper that (i) Multivariate control charts capitalize on the correlation between different correlated characteristics at the cost of losing simplicity, (ii) Individual univariate control charts provide better visual picture and clues for process improvement at the cost of missing out the possibility of capitalizing on the correlation between different correlated characteristics, (iii) Quadratic form based control charts exploit the correlation between different correlated quality characteristics at the cost of losing the benefit of interpretability and performance loss. He proposed an alternative approach which overcomes the aforementioned three problems keeping their respective benefits. He argued about his approach as: "In this approach, information on the dynamics of the process itself is used to uncover the directions of causality giving rise to the correlations in the data. This diagnosis in turn leads to prescriptions for the regression adjustment of different variables". He classified the processes into two main categories (i) Cascade: "where each variable that changes distribution affects those below but not above it", (ii) Without Cascade: "where each variable may undergo a distributional change without affecting any others". The focus of this article would be the processes without cascade property.

In the following sections (i) the design structure of the $V_{t}$ chart is developed for improved monitoring of a process variability following the pioneering work of 
Shewhart (1931), Pearson (1932), Pappanastos and Adams (1996), Ramalhoto and Morais (1999), Gonzalez and Viles (2000, 2001) and Riaz (2008a,b), (ii) the power curves are constructed as a performance measure of the $V_{t}$ chart following Scheffe (1949), Duncan (1951), Nelson (1985) and Riaz (2008a,b), (iii) the performance of the $V_{t}$ chart is compared with those of the conventional $S^{2}$ chart (a well-known Shewhart control chart) and the $V_{r}$ chart (a Shewhart type control chart proposed by Riaz 2008a,b) used for the same purpose following Tuprah and Ncube (1987), Acosta-Mejia et al. (1999), Ding et al. (2005) and Riaz (2008a).

\section{The proposed chart}

Assuming bivariate normality of $(Y, X)$ a relationship between $\sigma_{y}^{2}$ (the unknown process variability of the quality characteristic of interest $Y$ which is to be monitored) and $V_{t}$ (the ratio type estimator of $\sigma_{y}^{2}$ defined in (1)) is required to develop the structure of the proposed $V_{t}$ chart. Let $\left(y_{1}, x_{1}\right),\left(y_{2}, x_{2}\right), \ldots,\left(y_{n}, x_{n}\right)$ be a bivariate random sample of size $n$ from the bivariate normal distribution, and let $A$ be a random variable that defines a relationship between $\sigma_{y}^{2}$ and $V_{t}$ as:

$$
A=\frac{V_{t}}{\sigma_{y}^{2}},
$$

which helps in determining the parameters (i.e., the centerline, lower control limit and upper control limit) of the proposed $V_{t}$ chart.

Now if the distributional behavior of $A$ is available then the sample statistic $V_{t}$ can easily be used for testing hypotheses about shifts in $\sigma_{y}^{2}$. When $(Y, X)$ follows a bivariate normal distribution, the distributional behavior of $A$ depends only on $\rho_{y x}$ and $n$ (see Garcia and Cebrian 1996). The distributional behavior of $A$, in terms of its mean, standard error and quantile points, is required for developing the design structure of the $V_{t}$ chart, and is explored in the following paragraphs when $(Y, X)$ follows a bivariate normal distribution.

First, for the mean, applying expectations to (2) gives:

$$
E(A)=E\left(V_{t} / \sigma_{y}^{2}\right)=E\left(V_{t}\right) / \sigma_{y}^{2} .
$$

Here $E\left(V_{t}\right)$ can safely be replaced by its estimate $\bar{V}_{t}$ (the mean of the sample $V_{t}$ 's) using an appropriate number of random samples, as discussed in Hillier (1969) and Yang and Hiller (1970), from the process under study when the process is in the state of statistical control as written in Shewhart (1939, p. 26) just like $\bar{R}$ replaces $E(R)$ for the $R$ chart. Thus from (3) an estimate of $\sigma_{y}^{2}$, after rearranging the terms, is given as:

$$
\hat{\sigma}_{y}^{2}=\bar{V}_{t} / E(A)
$$

Let $E(A)=r_{0}$, on the same pattern as $v_{0}$ for $V_{r}$ chart in Riaz (2008a). As $V_{t}$ is unbiased estimator for $\sigma_{y}^{2}$ (see Garcia and Cebrian 1996) we have $r_{0}=1$. Thus (4) 
results in the following:

$$
\hat{\sigma}_{y}^{2}=\bar{V}_{t}
$$

Also from (3) we have:

$$
E\left(V_{t}\right)=\sigma_{y}^{2}
$$

Replacement of the estimate of $\sigma_{y}^{2}$ (given in (5)) in (6) gives:

$$
E\left(V_{t}\right) \simeq \bar{V}_{t}
$$

Thus, the $V_{t}$ chart works without constants, such as $d_{2}$ for the $R$ chart and $c_{4}$ for the $S$ chart, for an unbiased estimation of process variability using (5).

Secondly, for the standard error, let the standard deviation of $A$ (i.e., $\sigma_{A}$ ) be

$$
\sigma_{A}=r_{2}
$$

It is not easy to get analytical results for $r_{2}$ because $E\left(V_{t}^{2}\right)$ is difficult to obtain analytically. So simulation results are obtained for $r_{2}$ in this paper (In practice, simulation methods are often used to evaluate the expectation of a statistic, see Ross 1990). The coefficient $r_{2}$ entirely depends on $\rho_{y x}$ and $n$ for the case of bivariate normal distribution. Using 10,000 random samples generated from the standard bivariate normal distribution without loss of generality, the results of $r_{2}$ have been obtained, for different combinations of $\rho_{y x}$ and $n, 1,000$ times for each combination. Based on these results the mean values of $r_{2}$, along with their respective standard errors, are provided in Table 1 for $n=5,6, \ldots, 15,20,25,30,50,100$ at some representative values of $\rho_{y x}$, in the Appendix. Similar results can easily be obtained for any combination of $\rho_{y x}$ and $n$.

Also taking the variance of $A$ followed by simplification gives the expression for $\sigma_{A}$ as:

$$
\sigma_{A}=\sigma_{V_{t}} / \sigma_{y}^{2}
$$

where $\sigma_{V_{t}}$ represents the standard deviation of the distribution of the sample statistic $V_{t}$.

Substituting (8) into (9) and rearranging yields the following result for $\sigma_{V_{t}}$ :

$$
\sigma_{V_{t}}=r_{2} \sigma_{y}^{2}
$$

Substituting the estimate for $\sigma_{y}^{2}$, given in (5), into (10), the estimate for $\sigma_{V_{t}}$ is given as:

$$
\hat{\sigma}_{V_{t}}=r_{2} \bar{V}_{t}
$$

The expression in (11) is similar to the expression for $\hat{\sigma}_{R}$ of the $R$ chart as provided in Alwan (2000, p. 394). 
An approximation for $\sigma_{V_{t}}$, when $(Y, X)$ follows a bivariate normal distribution, is given as (see Garcia and Cebrian 1996):

$$
\sigma_{V_{t}} \simeq \sqrt{2 \sigma_{y}^{4}\left(1-\rho_{y x}^{4}\right) / n}
$$

Consequently,

$$
r_{2} \simeq \sqrt{2\left(1-\rho_{y x}^{4}\right) / n}
$$

This approximation result (13) works very well asymptotically; however, for the case of very small values of $n$ it does not provide a good approximation as can be seen from Table 1 in the Appendix.

Lastly, for the quantile points of the distribution of $A$, let $A_{a}$ represents the ath quantile point of the distribution of $A$ (i.e., the point where $A$ completes $a \%$ area). The analytical results for $A_{a}$ are difficult to obtain so simulation results are obtained for $A_{a}$. For a bivariate normal distribution of $(Y, X)$, the quantile points of the distribution of $A$ entirely depend on $\rho_{y x}$ and $n$. Using the same 10,000 simulated random samples, results of $A_{a}$ have been obtained (such as the quantile points of $W=R / \sigma$ that determine the values of the control limits of the $R$ chart and the power of the chart) following Pearson (1932), for different combinations of $\rho_{y x}$ and $n, 1000$ times for each combination. Based on these results, the mean values of some commonly used quantile points, along with their respective standard errors, are provided for $n=$ $5,6, \ldots, 15,20,25,30,50,100$ in Tables 2, 3, 4, 5, 6, 7, 8, 9, 10 and 11 at some representative values of $\rho_{y x}$, in the Appendix. Similar results can easily be obtained for any combination of $\rho_{y x}$ and $n$. These quantile points help in determining the control limits and the power of the proposed $V_{t}$ chart to detect shifts in the process variability $\sigma_{y}^{2}$. The distributional behavior of $A$ is not symmetrical at least for small values of $n$ as is obvious from Tables 2, 3, 4, 5, 6, 7, 8, 9, 10 and 11 in the Appendix. Asymptotically, $A$ is normally distributed, $N\left(1,2\left(1-\rho_{y x}^{4}\right) / n\right)$ (see Garcia and Cebrian 1996). The details regarding the asymptotic properties (mean, standard deviation and sampling distribution) of the sample statistic $V_{t}$ (or $A$ ), reported and used in this paper, may be seen in Isaki (1983) and Garcia and Cebrian (1996).

It is observed that for a given value of $\rho_{y x}$ the distributional behavior of $A$ (at least in terms of its mean, standard error and quantile points) remains the same irrespective of the sign of $\rho_{y x}$. Thus, the design structure of the proposed $V_{t}$ chart is function of $\left|\rho_{y x}\right|$ and $n$.

Now, based on the results obtained in Sect. 2, the parameters of the proposed $V_{t}$ chart are discussed in the following section.

\section{Parameters of the proposed chart}

The central line $(C L)$, lower control limit $(L C L)$ and upper control limit $(U C L)$ are the three parameters of any Shewhart type control chart. There are two approaches to express these parameters namely, the probability limits approach and the 3-sigma limits 
approach. In case of an asymmetric distributional behavior of a relevant estimator the probability limits approach is preferred. If the distributional behavior of a relevant estimator is nearly symmetric then the 3-sigma limits approach is a good alternative. The parameters of the proposed $V_{t}$ chart using both the approaches are expressed in the following two subsections. Following Shewhart's recommendations, ideally 2030 initial random samples for Phase-I are required to compute the parameters of the proposed chart.

\subsection{Probability limits approach}

The value $\bar{V}_{t}$ corresponds to $C L$ of the proposed $V_{t}$ chart just like $\bar{R}$ for the $R$ chart provided in Alwan (2000, p. 347) and $\bar{S}$ for the $S$ chart provided in Alwan (2000, p. 362). Assuming the probability of making a Type-I error to be less than a specified value say $\alpha$, then the control limits (which are actually true probability limits) for the proposed $V_{t}$ chart are defined as:

$$
\left.\begin{array}{l}
L C L=V_{t_{l}} \quad \text { with } \quad P_{n}\left(V_{t}=V_{t_{l}}\right) \leq \alpha_{l} \\
U C L=V_{t_{u}} \quad \text { with } \quad P_{n}\left(V_{t}=V_{t_{u}}\right) \geq 1-\alpha_{u}
\end{array}\right\}
$$

where $\alpha=\alpha_{l}+\alpha_{u}$ and $P_{n}$ represents the cumulative distribution function for a given value of $n$.

Now, using (2) and (5) in (14) and with simplification gives the following control limits:

$$
\left.\begin{array}{l}
L C L=V_{t_{l}}=A_{l} \overline{V_{t}} \quad \text { with } \quad P_{n}\left(A=A_{l}\right) \leq \alpha_{l} \\
U C L=V_{t_{u}}=A_{u} \overline{V_{t}} \quad \text { with } \quad P_{n}\left(A=A_{u}\right) \geq 1-\alpha_{u}
\end{array}\right\},
$$

Thus, the quantile points of the distribution of $A$ and the average of sample $V_{t}$ 's (i.e., $\bar{V}_{t}$ ) allow the setting of true probability limits of the proposed $V_{t}$ chart.

\subsection{Three-sigma limits approach}

If a normal approximation to the distribution of $A$ is used then the parameters of the proposed $V_{t}$ chart with the usual 3-sigma control limits are given as:

$$
\left.\begin{array}{l}
U C L=\overline{V_{t}}+3 \sigma_{V_{t}} \\
C L=\overline{V_{t}} \\
L C L=\overline{V_{t}}-3 \sigma_{V_{t}}
\end{array}\right\},
$$

Using (10) in (16) and then substituting result (5) gives the following result: 


$$
\left.\begin{array}{l}
U C L=\overline{V_{t}}+3 r_{2} \overline{V_{t}} \\
C L=\overline{V_{t}} \\
L C L=\overline{V_{t}}-3 r_{2} \overline{V_{t}}
\end{array}\right\},
$$

where values of $r_{2}$ are provided in Table 1 in the Appendix.

The validity of these 3 -sigma limits based parameters of the proposed $V_{t}$ chart depends on how close the normal approximation is to the true distribution of $A$.

For small values of $n$, sometimes the $L C L$ results in a negative value. A negative value for a variability measure has no realistic meaning. Therefore, in such situations the $L C L$ is assigned the value of 0 (as is done for the range statistic in the $R$ chart, see Alwan (2000, p. 355)).

After deciding the control structure, for a given significance level, by either the probability limit approach or the 3-sigma limit approach, the sample statistic $V_{t}$ is plotted against the time order of the samples. If all of the sample $V_{t}$ 's lie within the control limits, there is reasonable evidence to conclude that there is no shift in the process variability $\sigma_{y}^{2}$ and the process is stable at $\bar{V}_{t}$. Otherwise some assignable cause or causes are at work causing a shift in the process variability $\sigma_{y}^{2}$.

To address specifically small and moderate shifts: (i) the runs rules [as discussed by Nelson (1984), Wheeler (1995), Quesenberry (1997)] may be supplemented to the basic structure of the $V_{t}$ chart developed in this paper. As a result the risk of false alarms is increased, (ii) EWMA and CUSUM schemes may be developed based on the sample statistic $V_{t}$ (an area for further research).

"The situations where knowledge of the properties of auxiliary population is lacking, a larger first phase sample is observed only on the auxiliary characteristic(s). The first phase sample is used to furnish good estimates for the characteristics of the auxiliary population. A sub-sample (also called second phase sample) from the initial sample is selected for observing the variable of interest. Information collected on the two samples is then used to construct estimators for the parameter under consideration" see Singh and Mangat (1996). This is known as two phase sampling or double sampling. In case of unknown properties of the auxiliary characteristic(s), the case of double sampling may also be seen in Yu and Lam (1997) and Singh et al. (2004).

Now in the following section, the performance of the developed design structure of the $V_{t}$ chart is compared with those of the $S^{2}$ and $V_{r}$ charts as given in Riaz (2008a).

\section{Comparisons}

In this section, comparisons of the means, standard errors of the random variables used in the $V_{t}, V_{r}$ and $S^{2}$ charts and the power curves of these charts are provided. The random variable used for the $V_{t}$ chart of this paper is $A$ and its mean and standard error are $r_{0}$ and $r_{2}$ respectively. The corresponding random variable used for the $V_{r}$ chart from Riaz (2008a) is $D$ and its mean and standard error are $v_{0}$ and $v_{1}$ respectively, and the corresponding random variable used for the $S^{2}$ chart is $J$ and its mean and standard error are $u_{0}$ and $u_{1}$ respectively (see Riaz 2008a). 
Firstly, the comparison of means reveals that $r_{0}=u_{0}=1$ whereas $v_{0}$ deviates from 1 at least for small values of $\left|\rho_{y x}\right|$ and $n$. The deviation of the means $\left(r_{0}, v_{0}\right.$ and $\left.u_{0}\right)$ from 1 reveals the extent of biasness of the estimators used in $V_{t}, V_{r}$ and $S^{2}$ charts respectively. Thus, the $V_{t}$ and $S^{2}$ charts need no constant, such as $v_{0}$ for the $V_{r}$ chart, for unbiased estimation of the process variability $\sigma_{y}^{2}$.

Secondly, the values of standard errors $r_{2}, v_{1}$ and $u_{1}$ differ depending on $\left|\rho_{y x}\right|$ and $n$. It is observed that: (i) $r_{2}$ remains smaller than $u_{1}$ for all combinations of $\left|\rho_{y x}\right|$ and $n$, and the difference keeps increasing with an increase in either $\left|\rho_{y x}\right|$ or $n$; (ii) $r_{2}$ remains smaller than $v_{1}$ for all combinations of $\left|\rho_{y x}\right|$ and $n$, and the difference keeps decreasing with an increase in either $\left|\rho_{y x}\right|$ or $n$; (iii) for larger values of $\left|\rho_{y x}\right|$ or $\mathrm{n}, r_{2}$ and $v_{1}$ become very close to each other; (iv) for small values of $\left|\rho_{y x}\right|, v_{1}$ is larger than $u_{1}$ for a given value of $n$, and $v_{1}$ becomes smaller than $u_{1}$ with an increase in $\left|\rho_{y x}\right|$ as can be seen from Riaz (2008a).

Lastly, the efficiency of the $V_{t}$ chart as compared to those of the $V_{r}$ and $S^{2}$ charts has been examined using power curves as a performance measure. As the focus of the proposal is on Phase-I quality control, so power curves have been used as a performance measure (in contrast to Phase-II quality control where Average Run Length (ARL) is used as a performance measure) of the control charts following Albers and Kallenberg (2006) and Riaz (2008a,b). As the distributional behaviors of $A, D$ and $J$ are not symmetrical, at least for smaller values of $n$ so we used the probability limits approach for the three charts to set the control limits for a given significance level $(\alpha)$. Using their respective control structures, the probability limits of the $V_{t}, V_{r}$ and $S^{2}$ charts have been obtained for different combinations of $\left|\rho_{y x}\right|$ and $n$ with different significance levels, and the power curves for the three charts have been constructed. The power curves of the three charts, for $n=15$ and 25, are produced here, for examination purposes, at a low, a moderate and a high value of $\left|\rho_{y x}\right|$ in the following Figs. 1a-c and $2 \mathrm{a}-\mathrm{c}$, respectively (using $\alpha=0.002$ ).

In the above figures, the curves referred to as $S^{2}, V_{r}$ and $V_{t}$ represent the power curve of the $S^{2}, V_{r}$ and $V_{t}$ charts respectively. A similar behavior, as shown in the above figures, is observed for other combinations of $\left|\rho_{y x}\right|$ and $n$. The performance of the three charts differ depending on $\left|\rho_{y x}\right|$ and $n$ as can be seen from above figures. In general, the following points are observed:

$V_{t}$ Chart versus $S^{2}$ chart: The discriminatory power of the $V_{t}$ chart is higher than that of the $S^{2}$ chart for all combinations of $\left|\rho_{y x}\right|$ and $n$ as obvious from the above figures. The gain in terms of the discriminatory power for the $V_{t}$ chart, as compare to the $S^{2}$ chart, keeps increasing with an increase in either $\left|\rho_{y x}\right|$ or $n$ as obvious from the above figures. For $\left|\rho_{y x}\right|=0$ the power curves of the two charts coincide while for all $\left|\rho_{y x}\right|>0$, the $V_{t}$ chart remains superior to the $S^{2}$ chart for all values of $n$.

$V_{t}$ Chart versus $V_{r}$ chart: The discriminatory power of the $V_{t}$ chart is higher than that of the $V_{r}$ chart for all combinations of $\left|\rho_{y x}\right|$ and $n$ as obvious from the above figures. Difference in the power curves of the two charts keeps decreasing with an increase in either $\left|\rho_{y x}\right|$ or $n$ as obvious from the above figures. For very large values of $\left|\rho_{y x}\right|$ or $n$, power curves of the two charts almost coincide as obvious from the above figures. 

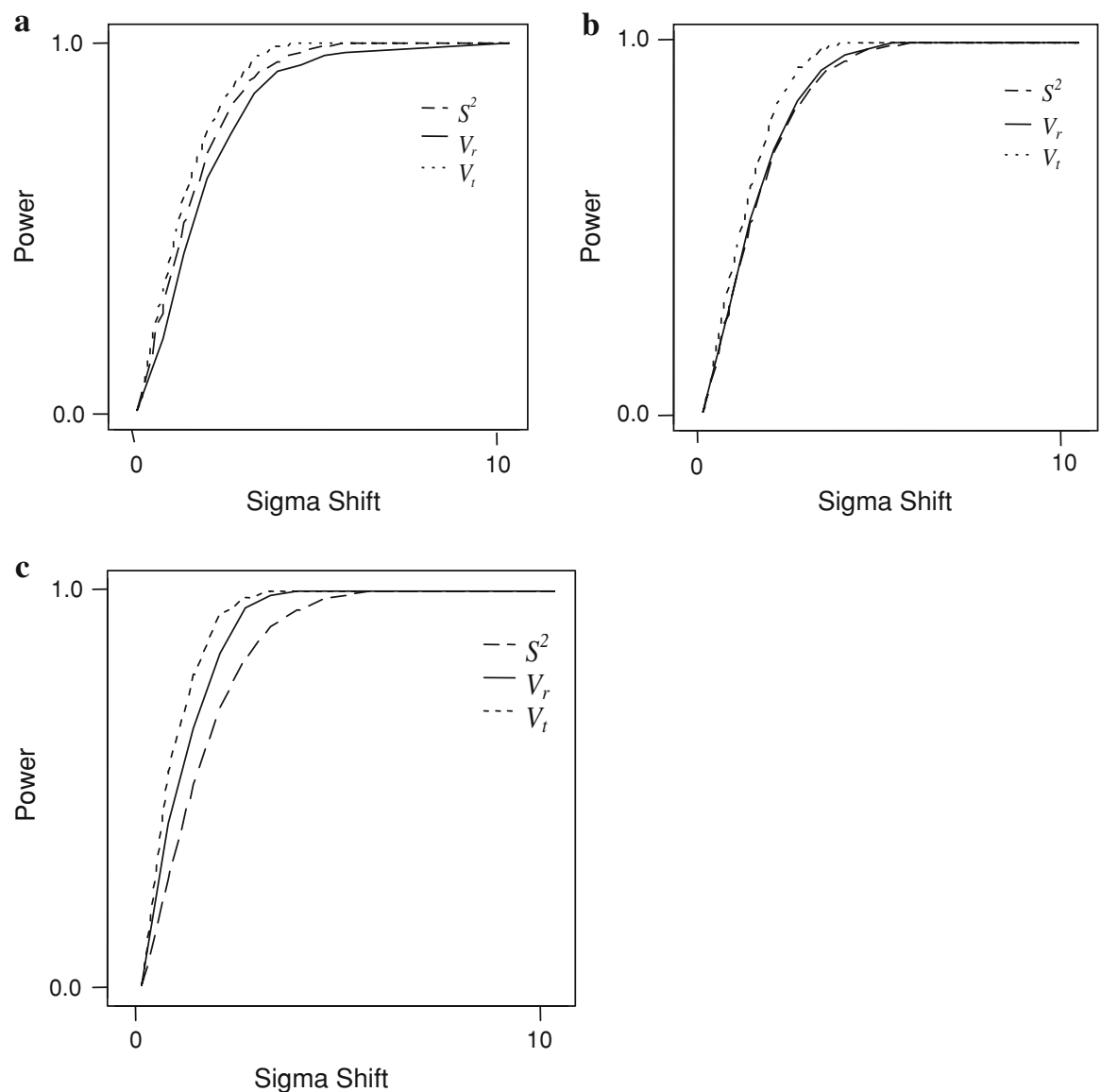

Fig. 1 a Power curves of the $V_{t} V_{r}$ and $S^{2}$ charts for $n=15,\left|\rho_{y x}\right|=0.30$ and $\alpha=0.002$. b Power Curves of the $V_{t}, V_{r}$ and $S^{2}$ charts for $n=15,\left|\rho_{y x}\right|=0.70$ and $\alpha=0.002$. $\mathbf{c}$ Power Curves of the $V_{t}, V_{r}$ and $S^{2}$ charts for $n=15,\left|\rho_{y x}\right|=0.90$ and $\alpha=0.002$

$V_{r}$ Chart versus $S^{2}$ chart: The discriminatory power of the $V_{r}$ chart is conditionally higher than that of the $S^{2}$ chart, conditioned on $\left|\rho_{y x}\right|$ and $n$. For each value of $n$ there exists a value of $\left|\rho_{y x}\right|$ below which the $V_{r}$ chart remains less powerful than the $S^{2}$ chart and above which the $V_{r}$ chart becomes more powerful than the $S^{2}$ chart as obvious from the above figures. The smallest value of $\left|\rho_{y x}\right|$, for a sample of size $n$, above which $V_{r}$ chart outperforms the $S^{2}$ chart for detecting shifts (especially moderate to large shifts) in process variability are given in Riaz (2008a).

Thus, the proposed chart of this paper (i.e., the $V_{t}$ chart) outperforms the $V_{r}$ and $S^{2}$ charts without any condition on $\left|\rho_{y x}\right|$ and $n$, as are required for the $V_{r}$ chart to outperform the $S^{2}$ chart and are given in Riaz (2008a). This is a major advantage of the proposed $V_{t}$ chart over the $V_{r}$ chart, and hence the $V_{t}$ chart is an improvement over the $V_{r}$ chart. 

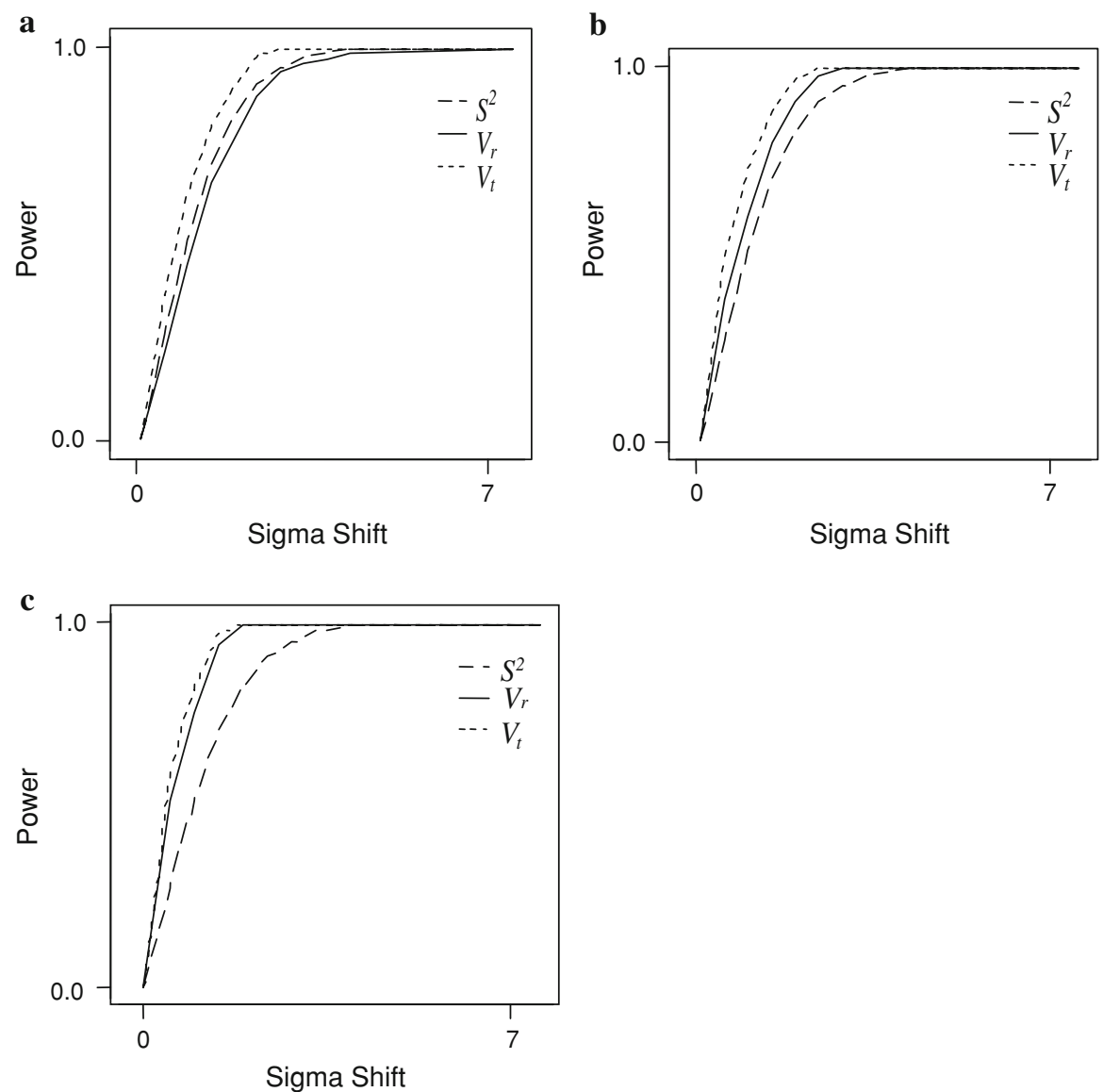

Fig. 2 a Power curves of the $V_{t}, V_{r}$ and $S^{2}$ charts for $n=25,\left|\rho_{y x}\right|=0.30$ and $\alpha=0.002$. b Power curves of the $V_{t}, \mathrm{~V}_{r}$ and $S^{2}$ charts for $n=25,\left|\rho_{y x}\right|=0.70$ and $\alpha=0.002$. $\mathbf{c}$ Power curves of the $V_{t}, \mathrm{~V}_{r}$ and $S^{2}$ charts for $n=25,\left|\rho_{y x}\right|=0.90$ and $\alpha=0.002$

\section{Conclusions}

The proposal of this article is a Shewhart type process variability control chart, focusing Phase-I quality control. The proposed $V_{t}$ chart uses the information on a single auxiliary variable for monitoring the process variability of a quality characteristic of interest. The $V_{t}$ chart outperforms the $S^{2}$ and $V_{r}$ charts for detecting shifts (especially of moderate and larger magnitudes because the Shewhart control charts target such shifts) in the process variability $\sigma_{y}^{2}$. It is observed that the performance of the $V_{t}$ chart, in terms of discriminatory power, improves with an increase in either $\left|\rho_{y x}\right|$ or $n$. The proposed $V_{t}$ chart is an improvement over the $V_{r}$ chart in the sense that its design structure is free from the conditions on $\left|\rho_{y x}\right|$ and $n$ to outperform the $S^{2}$ and $V_{r}$ charts, as are required for the $V_{r}$ chart to outperform the $S^{2}$ chart as given in Riaz (2008a).

Acknowledgments The authors are grateful to the editor and the referees for their recommendations and proposals which helped in improving substantially, the earlier version of this article. 
Open Access This article is distributed under the terms of the Creative Commons Attribution Noncommercial License which permits any noncommercial use, distribution, and reproduction in any medium, provided the original author(s) and source are credited.

\section{Appendix}

Note: In the following tables the results (in bold) are reported up to five decimal places. The value reported below each result is the standard error (reported up to six decimal places) for the result of each cell, reported to show precision of the result of each cell.

Table 1 Control chart coefficient $r_{2}$ of the $V_{t}$ chart

\begin{tabular}{|c|c|c|c|c|c|c|c|c|c|c|}
\hline \multirow[t]{2}{*}{$n$} & \multicolumn{10}{|l|}{$\left|\rho_{y x}\right|$} \\
\hline & 0.10 & 0.20 & 0.30 & 0.40 & 0.50 & 0.60 & 0.70 & 0.80 & 0.90 & 0.99 \\
\hline \multirow[t]{2}{*}{5} & 0.70753 & 0.70632 & 0.70558 & 0.70475 & 0.70582 & 0.70387 & 0.70486 & 0.70268 & 0.59524 & 0.24717 \\
\hline & 0.000632 & 20.000906 & 0.000582 & 20.000166 & 50.000202 & 0.000470 & 0.000119 & 0.000274 & 0.000182 & 0.000135 \\
\hline \multirow[t]{2}{*}{6} & 0.63211 & 0.63188 & 0.63119 & 0.63078 & 0.63004 & 0.62924 & 0.61579 & 0.58160 & 0.57079 & 0.16863 \\
\hline & 0.000213 & 30.000267 & 0.000299 & 0.000297 & 70.000653 & 30.000311 & 0.000320 & 0.000613 & 0.000217 & 0.000217 \\
\hline \multirow[t]{2}{*}{7} & 0.57579 & 0.57281 & 0.57127 & 0.57005 & 0.56931 & 0.56329 & 0.55442 & 0.50565 & 0.41209 & 0.14704 \\
\hline & 0.000198 & 80.000338 & 0.000137 & 70.000872 & 20.000747 & 70.000242 & 0.000188 & 0.00 & 0.00 & 0.000149 \\
\hline \multirow[t]{2}{*}{8} & 0.53373 & 0.53217 & 0.53180 & 0.53004 & 0.52975 & 0.52583 & 0.50252 & 0.45140 & 0.36337 & 0.12418 \\
\hline & 0.000543 & 30.000229 & 0.000441 & 10.000518 & 30.000524 & 0.000511 & 0.000407 & 0.000218 & 0.000398 & 0.000213 \\
\hline \multirow[t]{2}{*}{9} & 0.50006 & 0.49847 & 0.49523 & 0.49260 & 0.48988 & 0.48698 & 0.47361 & 0.41428 & 0.32915 & 0.11247 \\
\hline & 0.000447 & 70.000558 & 0.000102 & 20.000774 & 40.000669 & 0.000663 & 30.000100 & 0.0004 & 0.0 & 138 \\
\hline \multirow[t]{2}{*}{10} & 0.47077 & 0.46809 & 0.46260 & 0.46193 & 0.46007 & 0.45767 & 0.43696 & 0.38489 & 0.30250 & 0.10539 \\
\hline & 0.000369 & 9.000207 & 0.000235 & 50.000 & 0.000238 & 30.0004 & 0.0003 & 0.0003 & 0.0004 & 0.0 \\
\hline \multirow[t]{2}{*}{11} & 0.44561 & 0.44219 & 0.44067 & 0.43933 & 0.43556 & 0.42990 & 0.40589 & 0.36401 & 0.28475 & 0.09993 \\
\hline & 0.000824 & 40.0001724 & 40.00 & 50. & 0.0 & +0.00 & 50.00 & 0.0 & 0 & 0 \\
\hline \multirow[t]{2}{*}{12} & 0.42465 & 0.42221 & 0.42182 & 0.42013 & 0.41970 & 0.40890 & 0.39020 & 0.34775 & 0.27647 & 0.09268 \\
\hline & 0.0004 & 20.000668 & 0.000338 & 0.0006 & +0.000 & 0.0001 & 0.000363 & 0.0005 & 0. & 0. \\
\hline \multirow[t]{2}{*}{13} & 0.40697 & 0.40447 & 0.40181 & 0.40001 & 0.39766 & 0.39090 & 0.37008 & 0.33552 & 0.25719 & 0.08828 \\
\hline & 0.000943 & 30.000410 & 0.000581 & 0.0002 & 30.000 & 50.000 & 0.0004 & 0.00 & 0.0 & 36 \\
\hline \multirow[t]{2}{*}{14} & 0.39123 & 0.39064 & 0.39001 & 0.38943 & 0.38397 & 0.37672 & 0.35071 & 0.31160 & 0.24882 & 0.08613 \\
\hline & 0.000708 & 80.000317 & 0.000501 & 0.0004 & 0.0005 & 0.0002 & 0.0005 & 0.0007 & 0.0004 & 0.000299 \\
\hline \multirow[t]{2}{*}{15} & 0.37674 & 0.37532 & 0.37341 & 0.37165 & 0.37068 & 0.35931 & 0.34013 & 0.30702 & 0.23564 & 0.07995 \\
\hline & 0.00028 & 60.000156 & 0.000228 & 0.000355 & 50.00 & 0.000670 & 0.000258 & 0.000 & 0.000278 & 0.000748 \\
\hline \multirow[t]{2}{*}{20} & $\mathbf{0 . 3 2 3 5 7}$ & 0.32296 & 0.32115 & 0.32062 & 0.31449 & 0.30869 & 0.29145 & 0.25402 & 0.19621 & 0.06797 \\
\hline & 0.000342 & 20.000765 & 0.000476 & 50.000713 & 30.000673 & 30.000409 & 0.000508 & 0.000499 & 0.000510 & 0.000395 \\
\hline \multirow[t]{2}{*}{25} & 0.28765 & 0.28498 & 0.28265 & 0.28009 & 0.28076 & 0.27319 & 0.25485 & 0.22524 & 0.17314 & 0.06072 \\
\hline & 0.00027 & 50.000532 & 0.000826 & 60.0 & 70.00 & 70.00 & 20.00 & 0.00 & 0.000 & 0.000657 \\
\hline \multirow[t]{2}{*}{30} & 0.26255 & 0.26240 & 0.26195 & 0.26058 & 0.25470 & 0.24487 & 0.23115 & 0.20562 & 0.15572 & 0.05439 \\
\hline & 0.000667 & 70.000237 & 0.000620 & 0.000215 & 50.000401 & 10.000636 & 0.000442 & 0.00448 & 0.000661 & 0.000225 \\
\hline \multirow[t]{2}{*}{50} & 0.20200 & 0.20189 & 0.20104 & 0.20042 & 0.19643 & 0.19244 & 0.17626 & 0.15456 & 0.11973 & 0.04064 \\
\hline & 0.00012 & 40.000114 & 0.000188 & 0.000746 & 50.000887 & 70.000198 & 0.000746 & 0.00330 & 0.000209 & 0.000541 \\
\hline \multirow[t]{2}{*}{100} & 00.14209 & 0.14201 & 0.14193 & 0.13958 & 0.13837 & 0.13241 & 0.12460 & 0.11054 & 0.08436 & 0.02841 \\
\hline & 0.00047 & 60.000366 & 0.000332 & 20.0006 & 0.000236 & 60.000817 & 0.000098 & 0.00068 & 0.0007 & 0.000713 \\
\hline
\end{tabular}


Table 2 Quantile points of the distribution of $A$ (when $\left|\rho_{y x}\right|=0.10$ )

\begin{tabular}{|c|c|c|c|c|c|c|c|c|c|c|}
\hline$n$ & $A_{0.01}$ & $A_{0.05}$ & $A_{0.10}$ & $A_{0.20}$ & $A_{0.25}$ & $A_{0.75}$ & $A_{0.80}$ & $A_{0.90}$ & $A_{0.95}$ & $A_{0.99}$ \\
\hline \multirow[t]{2}{*}{5} & 6964 & 7109 & 26051 & 1101 & & & 1.63983 & 2.06038 & 2.51979 & 82 \\
\hline & 0.000319 & 0.000446 & 0.000618 & 0.000572 & 0.000444 & 0.000372 & 0.000215 & 0.000362 & & 70.000692 \\
\hline \multirow[t]{2}{*}{6} & 0.08036 & 0.22402 & & 0.47094 & & & & & & 3.11161 \\
\hline & 0.000500 & & 0.0002 & 0.000623 & 0.00 & & & & & 558 \\
\hline \multirow[t]{2}{*}{7} & 0.14023 & 0.27146 & 0.37075 & 0.51501 & 0.57821 & 1.38968 & 1.48991 & 1.82010 & 2.17197 & 2.90139 \\
\hline & .000412 & 0.00 & 0.0006 & 70.0005 & 0.00 & & & & & -0 \\
\hline
\end{tabular}

$\begin{array}{lllllllllll}8 & 0.16000 & 0.30222 & 0.40007 & 0.53611 & 0.60008 & 1.37969 & 1.48989 & 1.81011 & 2.09040 & 2.73949\end{array}$

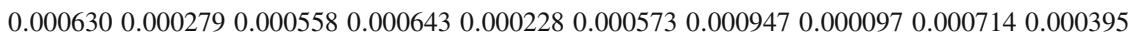

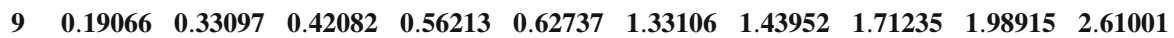

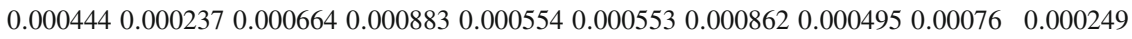

$\begin{array}{lllllllllll}10 & 0.21973 & 0.36066 & 0.46154 & 0.59850 & 0.65846 & 1.29998 & 1.40008 & 1.65987 & 1.91983 & 2.45491\end{array}$

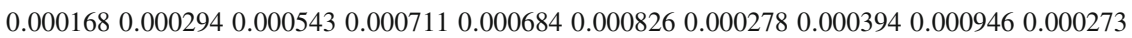

$\begin{array}{lllllllllll}11 & 0.24986 & 0.38859 & 0.49054 & 0.62010 & 0.67687 & 1.29875 & 1.38643 & 1.63985 & 1.86193 & 2.40157\end{array}$

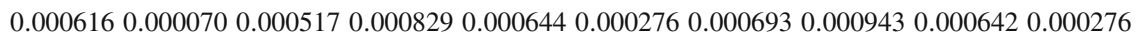

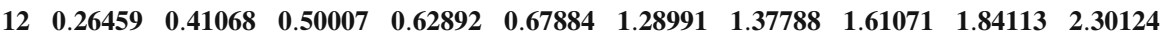

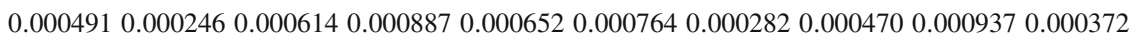

$\begin{array}{lllllllllll}13 & 0.28166 & 0.42297 & 0.52000 & 0.64690 & 0.69621 & 1.28167 & 1.35078 & 1.58822 & 1.79122 & 2.23504\end{array}$

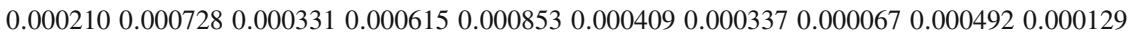

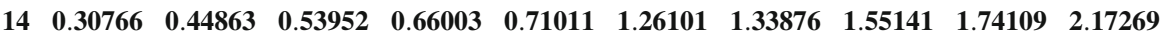

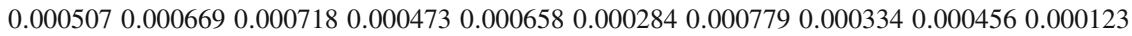

$\begin{array}{lllllllllll}15 & 0.32102 & 0.44937 & 0.54003 & 0.67020 & 0.72502 & 1.24701 & 1.32119 & 1.54684 & 1.73894 & 2.13209\end{array}$

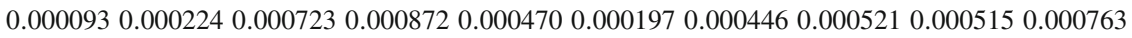

$\begin{array}{lllllllllll}20 & 0.39106 & 0.53061 & 0.60892 & 0.71928 & 0.76005 & 1.21943 & 1.28842 & 1.46809 & 1.62260 & 2.0148\end{array}$

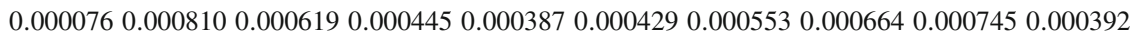

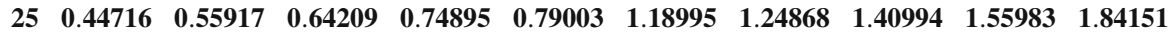
$\begin{array}{llllllllll}0.000422 & 0.000678 & 0.000582 & 0.000378 & 0.000816 & 0.000773 & 0.000661 & 0.000246 & 0.0009720 .000158\end{array}$

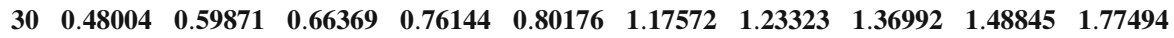
0.0002640 .0003370 .0005490 .0006680 .0001140 .0003830 .0000890 .0004270 .0006640 .000216

$\begin{array}{lllllllllll}50 & 0.58048 & 0.68017 & 0.72959 & 0.81005 & 0.84004 & 1.15995 & 1.19997 & 1.29411 & 1.38136 & 1.56080\end{array}$

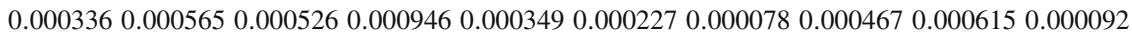

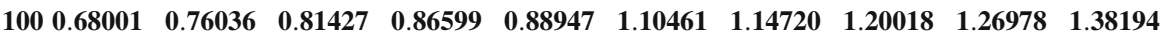

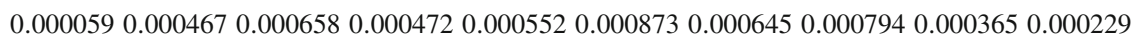


Table 3 Quantile points of the distribution of $A$ (when $\left|\rho_{y x}\right|=0.20$ )

\begin{tabular}{lllllllllll}
\hline$n$ & $A_{0.01}$ & $A_{0.05}$ & $A_{0.10}$ & $A_{0.20}$ & $A_{0.25}$ & $A_{0.75}$ & $A_{0.80}$ & $A_{0.90}$ & $A_{0.95}$ & $A_{0.99}$ \\
\hline $\mathbf{5}$ & $\mathbf{0 . 0 7 0 4 0}$ & $\mathbf{0 . 1 7 4 0 3}$ & $\mathbf{0 . 2 6 6 8 4}$ & $\mathbf{0 . 4 1 2 8 2}$ & $\mathbf{0 . 4 8 0 0 0}$ & $\mathbf{1 . 4 6 8 2 7}$ & $\mathbf{1 . 6 3 8 1 1}$ & $\mathbf{2 . 0 5 9 2 5}$ & $\mathbf{2 . 5 1 1 4 8}$ & $\mathbf{3 . 5 3 3 5 8}$ \\
& 0.000148 & 0.000651 & 0.000357 & 0.000623 & 0.000509 & 0.000987 & 0.000513 & 0.000098 & 0.000386 & 0.000066 \\
$\mathbf{6}$ & $\mathbf{0 . 0 8 9 8 5}$ & $\mathbf{0 . 2 3 3 0 7}$ & $\mathbf{0 . 3 2 7 3 7}$ & $\mathbf{0 . 4 7 3 8 1}$ & $\mathbf{0 . 5 3 9 3 7}$ & $\mathbf{1 . 3 9 9 9 7}$ & $\mathbf{1 . 5 5 6 4 4}$ & $\mathbf{1 . 9 4 0 5 9}$ & $\mathbf{2 . 3 0 0 5 7}$ & $\mathbf{3 . 1 0 1 0 4}$ \\
& 0.000781 & 0.000763 & 0.000465 & 0.000249 & 0.000666 & 0.000528 & 0.000729 & 0.000545 & 0.000298 & 0.000147
\end{tabular}

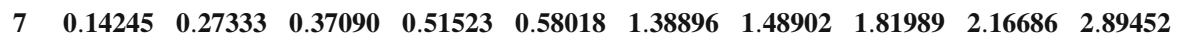

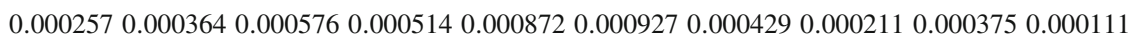

$\begin{array}{lllllllllll}8 & 0.16106 & 0.30866 & 0.40163 & 0.54959 & 0.60728 & 1.37771 & 1.48714 & 1.80183 & 2.08968 & 2.72343\end{array}$ $\begin{array}{lllllllllll}0.000312 & 0.000421 & 0.000752 & 0.000628 & 0.000478 & 0.000951 & 0.000713 & 0.000654 & 0.000826 & 0.000249\end{array}$

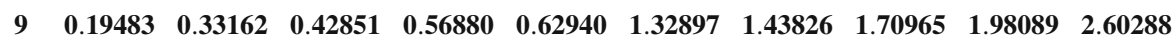

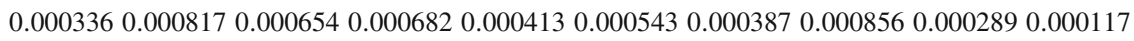

$\begin{array}{lllllllllll}10 & 0.22986 & 0.36286 & 0.46203 & 0.60320 & 0.66021 & 1.29997 & 1.39942 & 1.65794 & 1.91040 & 2.44236\end{array}$

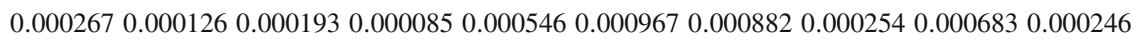

$\begin{array}{lllllllllll}11 & 0.25131 & 0.39321 & 0.49230 & 0.62338 & 0.68116 & 1.29660 & 1.38524 & 1.63780 & 1.85966 & 2.37942\end{array}$ $\begin{array}{lllllllll}0.000283 & 0.000369 & 0.000583 & 0.000173 & 0.000542 & 0.000357 & 0.000224 & 0.000394 & 0.0007640 .000284\end{array}$

$\begin{array}{lllllllllll}12 & 0.27060 & 0.41524 & 0.50082 & 0.63097 & 0.68125 & 1.28850 & 1.37187 & 1.60911 & 1.83484 & 2.29881\end{array}$ $\begin{array}{llllllllll}0.000255 & 0.000659 & 0.000512 & 0.000456 & 0.000673 & 0.000937 & 0.000448 & 0.000372 & 0.000652 & 0.000713\end{array}$

$\begin{array}{lllllllllll}13 & 0.28979 & 0.42971 & 0.52014 & 0.64998 & 0.70000 & 1.27874 & 1.34982 & 1.58548 & 1.78980 & 2.22255\end{array}$ $\begin{array}{lllllllllll}0.000429 & 0.000562 & 0.000389 & 0.000447 & 0.000538 & 0.000176 & 0.000277 & 0.000498 & 0.000531 & 0.000553\end{array}$

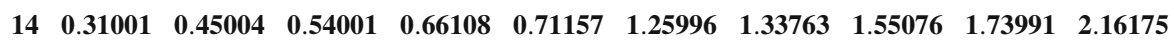
$\begin{array}{llllllllllll}0.000611 & 0.000289 & 0.000427 & 0.000392 & 0.000557 & 0.000492 & 0.000753 & 0.000628 & 0.000549 & 0.000941\end{array}$

$\begin{array}{lllllllllll}15 & 0.32611 & 0.45023 & 0.54032 & 0.67115 & 0.72603 & 1.24512 & 1.32013 & 1.54321 & 1.73620 & 2.12960\end{array}$ $\begin{array}{llllllllll}0.000578 & 0.000655 & 0.000283 & 0.000891 & 0.000354 & 0.000672 & 0.000477 & 0.000589 & 0.000861 & 0.000456\end{array}$

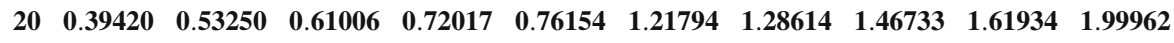
$\begin{array}{llllllllll}0.001046 & 0.000245 & 0.000823 & 0.000775 & 0.000619 & 0.000436 & 0.000367 & 0.000429 & 0.000955 & 0.000714\end{array}$

$\begin{array}{lllllllllll}25 & 0.44918 & 0.56000 & 0.64857 & 0.75006 & 0.79201 & 1.18981 & 1.24708 & 1.40704 & 1.54546 & 1.83287\end{array}$

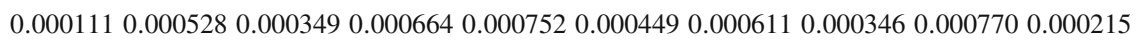

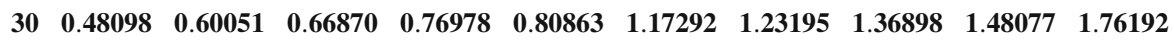

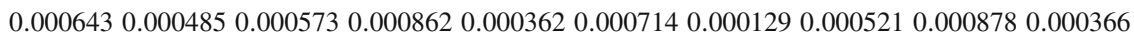

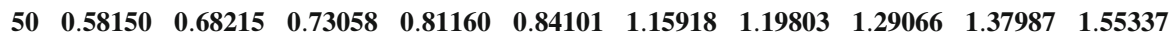

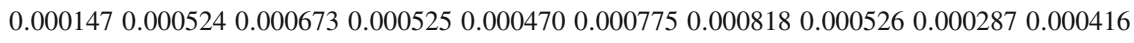

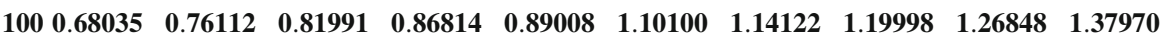
$\begin{array}{lllllllll}0.000741 & 0.000573 & 0.000419 & 0.000546 & 0.000854 & 0.000919 & 0.000744 & 0.0001220 .000327 & 0.000618\end{array}$ 
Table 4 Quantile points of the distribution of $A$ (when $\left|\rho_{y x}\right| x=0.30$ )

\begin{tabular}{lllllllllll}
\hline$n$ & $A_{0.01}$ & $A_{0.05}$ & $A_{0.10}$ & $A_{0.20}$ & $A_{0.25}$ & $A_{0.75}$ & $A_{0.80}$ & $A_{0.90}$ & $A_{0.95}$ & $A_{0.99}$ \\
\hline $\mathbf{5}$ & $\mathbf{0 . 0 7 6 9 9}$ & $\mathbf{0 . 1 8 5 0 1}$ & $\mathbf{0 . 2 7 2 9 3}$ & $\mathbf{0 . 4 1 9 2 0}$ & $\mathbf{0 . 4 8 9 3 7}$ & $\mathbf{1 . 4 6 7 3 6}$ & $\mathbf{1 . 6 3 7 2 0}$ & $\mathbf{2 . 0 5 6 9 9}$ & $\mathbf{2 . 5 1 0 0 4}$ & $\mathbf{3 . 5 2 4 9 4}$ \\
& 0.000497 & 0.000668 & 0.000357 & 0.000510 & 0.000088 & 0.000987 & 0.000492 & 0.000226 & 0.000693 & 0.000645 \\
$\mathbf{6}$ & $\mathbf{0 . 0 9 0 0 1}$ & $\mathbf{0 . 2 3 5 8 4}$ & $\mathbf{0 . 3 3 1 4 7}$ & $\mathbf{0 . 4 7 8 0 6}$ & $\mathbf{0 . 5 4 6 1 8}$ & $\mathbf{1 . 3 9 9 9 1}$ & $\mathbf{1 . 5 5 5 4 1}$ & $\mathbf{1 . 9 3 9 0 7}$ & $\mathbf{2 . 2 9 9 5 4}$ & $\mathbf{3 . 0 9 1 8 5}$ \\
& 0.000321 & 0.000645 & 0.000763 & 0.000918 & 0.000482 & 0.000673 & 0.000557 & 0.000279 & 0.000545 & 0.000197
\end{tabular}

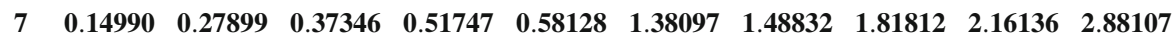

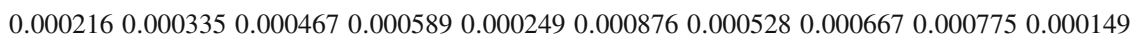

$\begin{array}{lllllllllll}8 & 0.16682 & 0.31146 & 0.40956 & 0.55588 & 0.61915 & 1.37504 & 1.48639 & 1.79994 & 2.08696 & 2.71775\end{array}$ $\begin{array}{lllllllllll}0.000524 & 0.000611 & 0.000288 & 0.000349 & 0.000476 & 0.000666 & 0.000683 & 0.000729 & 0.000645 & 0.000222\end{array}$

$\begin{array}{lllllllllll}9 & 0.21035 & 0.34001 & 0.43983 & 0.58105 & 0.641209 & 1.32867 & 1.43678 & 1.70820 & 1.97117 & 2.55611\end{array}$

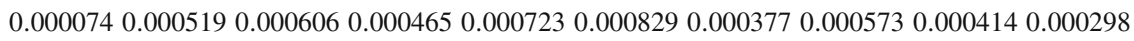

$\begin{array}{lllllllllll}10 & 0.23086 & 0.36959 & 0.46898 & 0.61076 & 0.66695 & 1.29942 & 1.39710 & 1.65178 & 1.90164 & 2.43462\end{array}$

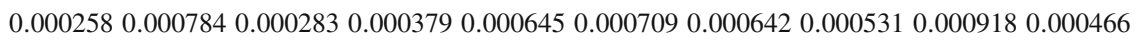

$\begin{array}{lllllllllll}11 & 0.25884 & 0.40134 & 0.49459 & 0.62620 & 0.68274 & 1.29186 & 1.38018 & 1.63232 & 1.85877 & 2.37251\end{array}$ $\begin{array}{llllllllll}0.000283 & 0.000447 & 0.000752 & 0.000492 & 0.000611 & 0.000498 & 0.000549 & 0.0004160 .000546 & 0.000620\end{array}$

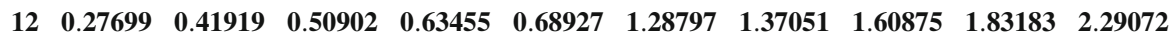
$\begin{array}{lllllllll}0.000450 & 0.00258 & 0.000209 & 0.000188 & 0.000476 & 0.000455 & 0.000675 & 0.0008720 .0009120 .000142\end{array}$

$\begin{array}{lllllllllll}13 & 0.29083 & 0.43005 & 0.52779 & 0.65102 & 0.70007 & 1.27081 & 1.34147 & 1.58064 & 1.78790 & 2.21657\end{array}$ $\begin{array}{lllllll}0.000086 & 0.0007160 .0002440 .000369 & 0.0007680 .0005820 .000900 & 0.0007060 .0006560 .000289\end{array}$

$\begin{array}{lllllllllll}14 & 0.31027 & 0.45165 & 0.54470 & 0.66727 & 0.71968 & 1.25987 & 1.33249 & 1.54974 & 1.73718 & 2.15721\end{array}$

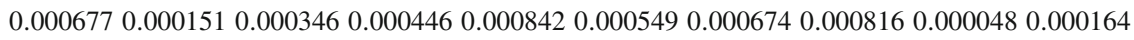

$\begin{array}{lllllllllll}15 & 0.32747 & 0.45446 & 0.54541 & 0.67772 & 0.73010 & 1.24051 & 1.31999 & 1.54174 & 1.73225 & 2.11012\end{array}$

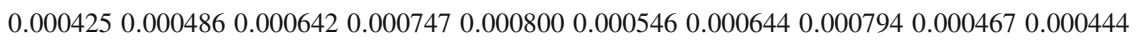

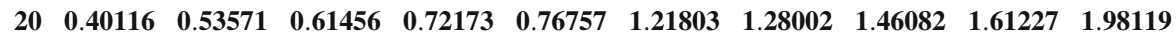
$\begin{array}{llllllllll}0.000545 & 0.000236 & 0.000287 & 0.000144 & 0.000761 & 0.000649 & 0.000346 & 0.000514 & 0.000410 & 0.000321\end{array}$

$\begin{array}{lllllllllll}25 & 0.45006 & 0.56186 & 0.65175 & 0.75120 & 0.79998 & 1.18642 & 1.24021 & 1.40079 & 1.54078 & 1.82341\end{array}$

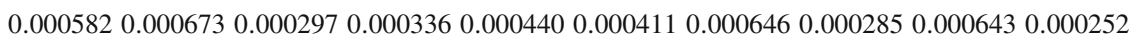

$\begin{array}{lllllllllll}30 & 0.48652 & 0.60806 & 0.67976 & 0.77004 & 0.81000 & 1.17001 & 1.23140 & 1.36294 & 1.47877 & 1.75656\end{array}$ $\begin{array}{lllllllll}0.000078 & 0.000165 & 0.000263 & 0.000209 & 0.000648 & 0.000771 & 0.000669 & 0.0004180 .000523 & 0.000413\end{array}$

$\begin{array}{lllllllllll}50 & 0.58877 & 0.68802 & 0.73867 & 0.81937 & 0.84856 & 1.15729 & 1.19088 & 1.28996 & 1.37282 & 1.54522\end{array}$ 0.0002840 .0006450 .0004460 .0002780 .0003520 .0003610 .0007400 .0005260 .0004270 .000197

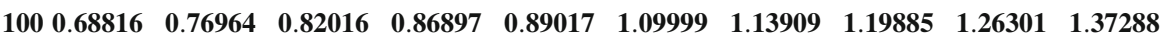
$\begin{array}{llllllllll}0.000415 & 0.000349 & 0.000527 & 0.000426 & 0.000658 & 0.000782 & 0.000453 & 0.000227 & 0.000674 & 0.000587\end{array}$ 
Table 5 Quantile points of the distribution of $A$ (when $\left|\rho_{y x}\right|=0.40$ )

\begin{tabular}{|c|c|c|c|c|c|c|c|c|c|c|}
\hline$n$ & $A_{0.01}$ & $A_{0.05}$ & $A_{0.10}$ & $A_{0.20}$ & $A_{0.25}$ & $A_{0.75}$ & $A_{0.80}$ & $A_{0.90}$ & $A_{0.95}$ & $A_{0.99}$ \\
\hline \multirow[t]{2}{*}{5} & 0.08074 & 0.18632 & 0.28386 & 0.42827 & 0.49977 & 1.46156 & 1.63632 & 2.05292 & 2.50341 & 3.51790 \\
\hline & 0.000112 & 0.000254 & 40.000639 & 0.000417 & 0.000633 & 0.000543 & 0.000887 & 0.000323 & 0.000451 & 0.000237 \\
\hline \multirow[t]{2}{*}{6} & 0.09866 & 0.23863 & 0.33753 & 0.49367 & 0.56171 & 1.39975 & 1.55038 & 1.93137 & 2.29275 & 3.08463 \\
\hline & 0.000365 & 0.000741 & 10.000258 & 0.000364 & 0.000419 & 0.000653 & 0.000742 & 0.000524 & 0.000448 & 0.000075 \\
\hline \multirow[t]{2}{*}{7} & 0.15447 & 0.28902 & 0.38528 & 0.53341 & 0.60050 & 1.36954 & 1.48153 & 1.81200 & 2.15489 & 2.87998 \\
\hline & 0.000616 & 0.000070 & 0.000517 & 0.000829 & 0.000644 & 0.000276 & 0.000693 & 0.000943 & 0.000258 & 0.000811 \\
\hline \multirow[t]{2}{*}{8} & 0.17532 & 0.31780 & 0.41809 & 0.56599 & 0.63521 & 1.37106 & 1.48011 & 1.79945 & 2.08382 & 2.70861 \\
\hline & 0.000407 & 0.000096 & 0.000448 & 0.000449 & 0.000623 & 0.000718 & 0.0 & 0.000354 & 0.0 & 082 \\
\hline \multirow[t]{2}{*}{9} & 0.21322 & 0.34937 & 0.44076 & 0.58778 & 0.64494 & 1.32187 & 1.43021 & 1.70109 & 1.96290 & 2.53612 \\
\hline & 0.000122 & 0.0006 & 0.000716 & 0.000663 & 0.000747 & 0.000 & 0.000326 & 0.00 & 0.00 & 0.000441 \\
\hline \multirow[t]{2}{*}{10} & 0.23495 & 0.37690 & 0.47672 & 0.61868 & 0.67680 & 1.29983 & 1.39019 & 1.64837 & 1.89621 & 2.42481 \\
\hline & 0.000645 & 0.000249 & 0.001501 & 0.000237 & 0.000412 & 0.000257 & 0.000473 & 0.000146 & 0.00 & 0.000115 \\
\hline \multirow[t]{2}{*}{11} & 0.26010 & 0.40438 & 0.49962 & 0.63009 & 0.69086 & 1.28818 & 1.37252 & 1.63029 & 1.85159 & 2.35129 \\
\hline & 0.000651 & 0.000491 & 0.000492 & 0.000897 & 0.000558 & 0.000149 & 0.000624 & 0.000773 & 0.000872 & 0914 \\
\hline \multirow[t]{2}{*}{12} & 0.28269 & 0.42277 & 0.51697 & 0.63873 & 0.69810 & 1.28281 & 1.36979 & 1.60171 & 1.82135 & 2.28684 \\
\hline & 0.0003 & +0.0004 & 0.0008 & 617 & 0.000767 & 0.0 & 0.0 & 0.0 & 0 & 379 \\
\hline \multirow[t]{2}{*}{13} & 0.29898 & 0.43978 & 0.53000 & 0.65504 & 0.70570 & 1.26905 & 1.33816 & 1.57101 & 1.77306 & 2.20609 \\
\hline & 0.000521 & 0.00 & 0.0 & 0.0 & 0.0 & 0. & 0 & 0 & 0 & 11 \\
\hline \multirow[t]{2}{*}{14} & 0.31440 & 0.45745 & 0.54739 & 0.67505 & 0.72623 & 1.25914 & 1.32999 & 1.54763 & 1.72980 & 2.14626 \\
\hline & 0.000226 & 50.000419 & 0.000327 & 0.000369 & 0.000456 & 0.000 & 0.000229 & 0.0003 & 0.00 & 521 \\
\hline \multirow[t]{2}{*}{15} & 0.33079 & 0.46893 & 0.55696 & 0.68294 & 0.73259 & 1.23987 & 1.31899 & 1.53262 & 1.72390 & 2.09970 \\
\hline & 0.000641 & 0.0007 & 0.0004 & 0.000253 & 0.000462 & 0.000 & 0.000645 & 0.000514 & 0. & 0.000141 \\
\hline \multirow[t]{2}{*}{20} & 0.41460 & 0.54686 & 0.62935 & 0.72879 & 0.77806 & 1.21092 & 1.27990 & 1.45373 & 1.60543 & 1.96382 \\
\hline & 0.000643 & 30.000 & 0.0005 & 0.000947 & 0.000097 & 0.000714 & 0.0003 & 0.000087 & 0.000215 & 0.000622 \\
\hline \multirow[t]{2}{*}{25} & 0.45806 & 0.57886 & 0.65762 & 0.75533 & 0.80005 & 1.18041 & 1.23873 & 1.38895 & 1.53041 & 1.81796 \\
\hline & 0.000245 & 0.000877 & 0.000366 & 0.000419 & 0.000552 & 0.000872 & 0.000673 & 0.000323 & 0.000416 & 0.000088 \\
\hline \multirow[t]{2}{*}{30} & 0.49038 & 0.61438 & 0.68402 & 0.77663 & 0.81377 & 1.16991 & 1.22300 & 1.35223 & 1.46860 & 1.74442 \\
\hline & 0.00 & 50 & 0.0 & 84 & 0.00 & 0 & 0 & 0. & 0 & 0346 \\
\hline \multirow[t]{2}{*}{50} & 0.59783 & 0.70076 & 0.74768 & 0.82539 & 0.85163 & 1.15157 & 1.18643 & 1.28374 & 1.36070 & 1.53734 \\
\hline & 0.000752 & 2.000020 & 0.000478 & 0.000951 & 0.000713 & 0.000654 & 0.000524 & 0.000114 & 0.000347 & 0.000310 \\
\hline \multirow[t]{2}{*}{100} & 0.69573 & 0.77455 & 0.82660 & 0.87316 & 0.89742 & 1.09979 & 1.13642 & 1.19261 & 1.25121 & 1.36893 \\
\hline & 0.000349 & 0.000664 & 0.000752 & 0.000449 & 0.000611 & 0.000346 & 0.000770 & 0.000412 & 0.000324 & 0.000542 \\
\hline
\end{tabular}


Table 6 Quantile points of the distribution of $A$ (when $\left|\rho_{y x}\right| x=0.50$ )

\begin{tabular}{|c|c|c|c|c|c|c|c|c|c|c|}
\hline$n$ & $A_{0.01}$ & $A_{0.05}$ & $A_{0.10}$ & $A_{0.20}$ & $A_{0.25}$ & $A_{0.75}$ & $A_{0.80}$ & $A_{0.90}$ & $A_{0.95}$ & $4_{0.99}$ \\
\hline \multirow[t]{2}{*}{5} & & 630 & 3964 & 282 & 2005 & 70 & 56 & & 11 & \\
\hline & 0.00018 & & & & & & & & & 221 \\
\hline \multirow[t]{2}{*}{6} & 0.10559 & 0.24484 & 0.34284 & 50025 & 57091 & 1.39924 & 83 & 65 & 75 & 522 \\
\hline & 0 & 0.000631 & ( & 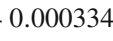 & & & 0.000463 & & & \\
\hline \multirow[t]{2}{*}{7} & 0.15914 & 0.29655 & 0.39200 & 0.54164 & 0.61229 & 1.36278 & 1.47799 & 179 & 659 & 765 \\
\hline & 0.0004 & & 10 & 0 & & 61 & 0.0 & & & 94 \\
\hline \multirow[t]{2}{*}{8} & וס & 0 & 8 & $\mathbf{0}$ & 10 & 1 & 38 & 09 & 80 & 40 \\
\hline & 0.000531 & 0 . & 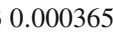 & ( & 0 & 72 & 0.0 & & & . \\
\hline \multirow[t]{2}{*}{9} & 18 & 0.35 & 46 & 598 & 07 & & & 70 & 02 & 168 \\
\hline & 0.000652 & & & 0 & 0 & 12 & 0.000887 & 70. & 02 & $03 / 4$ \\
\hline \multirow[t]{2}{*}{10} & 0.25143 & $\mathbf{0}$ & 4 & 71 & 7 & 5 & 099 & 06 & 01 & 2.39381 \\
\hline & 0.0 & 0.00052 & 0.00044 & 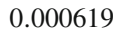 & 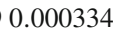 & 19 & 0. & & & 0553 \\
\hline \multirow[t]{2}{*}{11} & 0.27345 & 0.41 & 93 & 14 & 73 & 1.2 & 1.3 & 76 & 88 & 198 \\
\hline & 0.00066 & & & & & & & & & \\
\hline
\end{tabular}

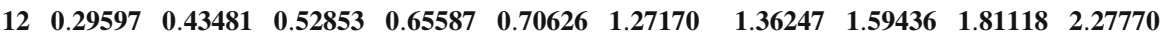

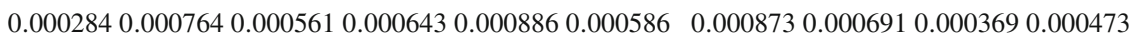

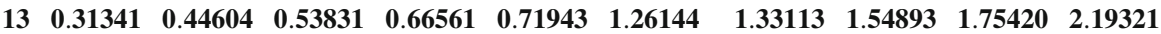
$\begin{array}{llllll}0.0013610 .000648 & 0.000294 & 0.000403 & 0.0001140 .000099 & 0.000351 & 0.0005240 .0003640 .000149\end{array}$

$\begin{array}{lllllllllll}14 & 0.33133 & 0.46642 & 0.55757 & 0.68323 & 0.73288 & 1.25095 & 1.32696 & 1.52711 & 1.72234 & 2.13094\end{array}$

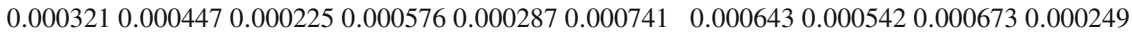

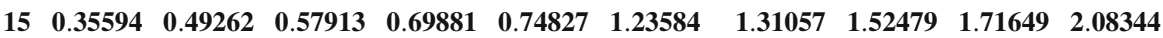
0.0002550 .0006730 .0003620 .001200 .0003690 .00041600 .0004170 .0006320 .0004110 .000366

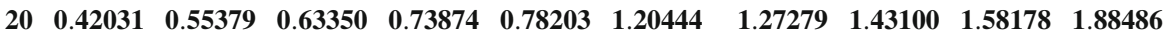

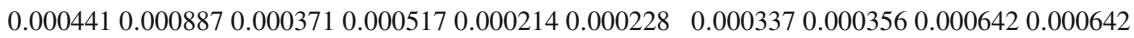

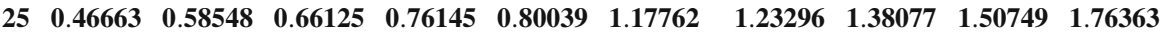
$\begin{array}{lllllll}0.000458 & 0.0001250 .000701 & 0.0006460 .000809 & 0.000132 & 0.000258 & 0.0003610 .000746 & 0.000858\end{array}$

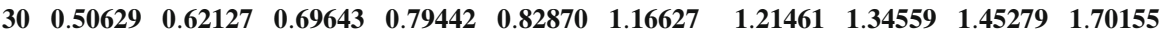
$\begin{array}{lllllll}0.000255 & 0.000446 & 0.000336 & 0.0007450 .000528 & 0.000361 & 0.000887 & 0.0006840 .0009720 .000336\end{array}$

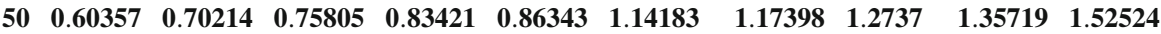

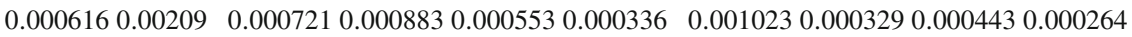

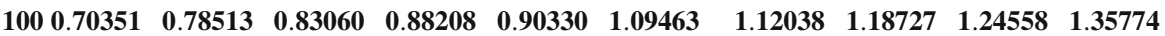

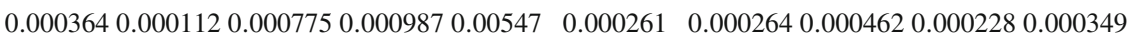


Table 7 Quantile points of the distribution of $A$ (when $\left|\rho_{y x}\right|=0.60$ )

\begin{tabular}{lllllllllll}
\hline$n$ & $A_{0.01}$ & $A_{0.05}$ & $A_{0.10}$ & $A_{0.20}$ & $A_{0.25}$ & $A_{0.75}$ & $A_{0.80}$ & $A_{0.90}$ & $A_{0.95}$ & $A_{0.99}$ \\
\hline
\end{tabular}

$\begin{array}{lllllllllll}5 & 0.09253 & 0.20776 & 0.30678 & 0.46457 & 0.54039 & 1.45570 & 1.61647 & 2.03974 & 2.48324 & 3.43849\end{array}$ 0.0004180 .0002210 .0008430 .0009020 .0003420 .0004110 .0006430 .0009420 .0007640 .000091

$\begin{array}{lllllllllll}6 & 0.11765 & 0.25643 & 0.35792 & 0.51824 & 0.58726 & 1.39744 & 1.53375 & 1.90131 & 2.27435 & 3.06561\end{array}$ $\begin{array}{llllllllllll}0.000116 & 0.000264 & 0.000461 & 0.000392 & 0.000543 & 0.000661 & 0.0009160 .000506 & 0.0001430 .000266\end{array}$

$\begin{array}{lllllllllll}7 & 0.17661 & 0.31949 & 0.42095 & 0.57036 & 0.63378 & 1.35820 & 1.46955 & 1.79085 & 2.13916 & 2.83694\end{array}$ $\begin{array}{lllllllllllllllll}0.000521 & 0.000072 & 0.000987 & 0.000367 & 0.000492 & 0.000114 & 0.000099 & 0.000351 & 0.000364 & 0.000431\end{array}$

$\begin{array}{lllllllllll}8 & 0.20004 & 0.34571 & 0.44684 & 0.60036 & 0.66085 & 1.34082 & 1.44146 & 1.72996 & 2.01856 & 2.63842\end{array}$ $\begin{array}{lllllllllllllllll}0.000369 & 0.000411 & 0.000873 & 0.000655 & 0.000392 & 0.000411 & 0.000747 & 0.000564 & 0.000336 & 0.000065\end{array}$

$\begin{array}{lllllllllll}9 & 0.23329 & 0.37253 & 0.47337 & 0.61796 & 0.68002 & 1.31624 & 1.41424 & 1.68791 & 1.92493 & 2.49204\end{array}$ 0.0008560 .0003640 .0002470 .0003360 .0004520 .0009130 .0004690 .0007140 .0006490 .000357

$\begin{array}{lllllllllll}10 & 0.25823 & 0.41299 & 0.50786 & 0.63974 & 0.69833 & 1.28960 & 1.37776 & 1.63969 & 1.88249 & 2.34757\end{array}$ $\begin{array}{llllllllllll}0.000229 & 0.000448 & 0.000114 & 0.000557 & 0.000641 & 0.000812 & 0.000643 & 0.000249 & 0.000944 & 0.000643\end{array}$

$\begin{array}{lllllllllll}11 & 0.27755 & 0.43206 & 0.52792 & 0.66223 & 0.71616 & 1.27757 & 1.36343 & 1.61392 & 1.81961 & 2.26617\end{array}$ 0.0002780 .0006690 .0008080 .0002540 .0005570 .0006190 .0006690 .0004410 .0006730 .000543

$\begin{array}{lllllllllll}12 & 0.31188 & 0.45503 & 0.54419 & 0.67318 & 0.72407 & 1.26940 & 1.35114 & 1.58369 & 1.77997 & 2.19720\end{array}$ $\begin{array}{llllllllllll}0.000573 & 0.000854 & 0.000919 & 0.000450 & 0.00258 & 0.000416 & 0.000546 & 0.000482 & 0.000673 & 0.000557\end{array}$

$\begin{array}{lllllllllll}13 & 0.32863 & 0.47025 & 0.56149 & 0.68407 & 0.73389 & 1.25473 & 1.32859 & 1.54276 & 1.73373 & 2.12238\end{array}$ $\begin{array}{llllllllllll}0.000632 & 0.000552 & 0.000966 & 0.000749 & 0.000546 & 0.000720 & 0.000638 & 0.000467 & 0.000228 & 0.000173\end{array}$

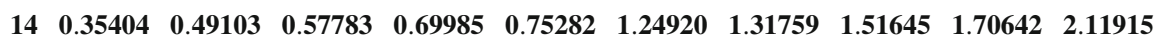
$\begin{array}{lllllllllllll}0.000081 & 0.000349 & 0.000542 & 0.000873 & 0.000558 & 0.000419 & 0.000673 & 0.000581 & 0.000664 & 0.000246\end{array}$

$\begin{array}{lllllllllll}15 & 0.36812 & 0.50477 & 0.59331 & 0.70971 & 0.75928 & 1.22984 & 1.30029 & 1.49272 & 1.66649 & 2.04678\end{array}$ $\begin{array}{lllllllllll}0.000229 & 0.000416 & 0.000744 & 0.000813 & 0.000681 & 0.000212 & 0.000517 & 0.000421 & 0.000244 & 0.000645\end{array}$

$\begin{array}{lllllllllll}20 & 0.43222 & 0.55514 & 0.63994 & 0.74404 & 0.78682 & 1.20138 & 1.26177 & 1.42613 & 1.56148 & 1.83603\end{array}$ $\begin{array}{lllllllllllll}0.000442 & 0.000576 & 0.000558 & 0.000643 & 0.000224 & 0.000673 & 0.000576 & 0.000883 & 0.000649 & 0.000246\end{array}$

$\begin{array}{lllllllllll}25 & 0.48472 & 0.60170 & 0.67522 & 0.77239 & 0.81172 & 1.17079 & 1.22408 & 1.37260 & 1.49763 & 1.75086\end{array}$ $\begin{array}{lllllllllllllll}0.000471 & 0.000622 & 0.000746 & 0.000511 & 0.000228 & 0.000376 & 0.000458 & 0.000512 & 0.000642 & 0.000097\end{array}$

$\begin{array}{lllllllllll}30 & 0.51572 & 0.63953 & 0.70815 & 0.80080 & 0.83779 & 1.16303 & 1.20727 & 1.33314 & 1.43737 & 1.66238\end{array}$ $\begin{array}{llllllllll}0.000673 & 0.000472 & 0.000673 & 0.000882 & 0.000919 & 0.000726 & 0.000573 & 0.000083 & 0.000128 & 0.0000149\end{array}$

$\begin{array}{lllllllllll}50 & 0.60970 & 0.71275 & 0.76999 & 0.84528 & 0.87318 & 1.13026 & 1.16802 & 1.26263 & 1.34648 & 1.51069\end{array}$ $\begin{array}{llllllllllll}0.000241 & 0.000627 & 0.000891 & 0.000349 & 0.000641 & 0.000549 & 0.000603 & 0.000249 & 0.000349 & 0.000549\end{array}$

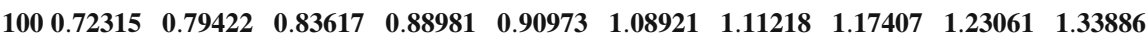
0.0005430 .0004170 .0002550 .0004260 .0005590 .0007490 .0004090 .0006670 .0004970 .000254 
Table 8 Quantile points of the distribution of $A$ (when $\left|\rho_{y x}\right|=0.70$ )

\begin{tabular}{|c|c|c|c|c|c|c|c|c|c|c|}
\hline$n$ & $A_{0.01}$ & $A_{0.05}$ & $A_{0.10}$ & $A_{0.20}$ & $A_{0.25}$ & $A_{0.75}$ & $A_{0.80}$ & $A_{0.90}$ & $A_{0.95}$ & $A_{0.99}$ \\
\hline \multirow[t]{2}{*}{5} & 0.10424 & 0.23205 & 0.33079 & 0.49787 & 0.58353 & 1.44860 & 1.59072 & 2.02327 & 2.45141 & 3.41911 \\
\hline & 0.0002347 & 70.0008916 & 50.000269 & 0.000913 & 30.000527 & 70.000369 & 90.000491 & 0.000098 & 0.0002 & 40.000162 \\
\hline \multirow[t]{2}{*}{6} & 0.15378 & 0.28914 & 0.39882 & 0.55783 & 0.62929 & 1.38124 & 1.50641 & 1.85509 & 2.19933 & 3.03838 \\
\hline & 0.000624 & 0.000369 & 0.000189 & 0.000729 & 90.000509 & 90.000651 & 10.000444 & 40.000608 & 0.0008 & 70.000114 \\
\hline \multirow[t]{2}{*}{7} & 0.18708 & 0.33467 & 0.42915 & 0.58632 & 0.65449 & 1.35515 & 1.46545 & 1.77039 & 2.05662 & 2.80257 \\
\hline & 0.000148 & 0.000258 & 0.000643 & 0.000510 & 0.000664 & 40.000806 & 60.000099 & 0.000226 & 0.000319 & 90.000080 \\
\hline \multirow[t]{2}{*}{8} & 0.23625 & 0.37027 & 0.47556 & 0.61772 & 0.67978 & 1.33087 & 1.43097 & 1.71811 & 1.96779 & 2.55939 \\
\hline & 0.000058 & 0.000668 & 0.000582 & 0.000669 & 90.000068 & 80.000987 & 70.000367 & 70.000492 & 0.000686 & 60.000558 \\
\hline \multirow[t]{2}{*}{9} & 0.26328 & 0.40551 & 0.50342 & 0.64578 & 0.70474 & 1.30831 & 1.40120 & 1.66481 & 1.91193 & 2.48411 \\
\hline & 0.0004489 & 90.000651 & 0.000887 & 0.000623 & 30.000088 & 80.000567 & 70.000492 & 20.000332 & 0.000386 & 60.000408 \\
\hline \multirow[t]{2}{*}{10} & 0.28730 & 0.42995 & 0.52809 & 0.66502 & 0.71646 & 1.28785 & 1.36942 & 1.61043 & 1.83518 & 2.30553 \\
\hline & 0.000500 & 0.000293 & 0.000461 & 0.000339 & 90.000065 & 50.000478 & 80.000658 & 0.000587 & 0.0 & 109 \\
\hline \multirow[t]{2}{*}{11} & 0.30966 & 0.46530 & 0.55194 & 0.67786 & 0.73122 & 1.27095 & 1.34316 & 1.56306 & 1.75764 & 2.21297 \\
\hline & 0.000049 & 0.000159 & 0.000357 & & 60.000964 & 40.000555 & 50.000390 & 0.000861 & & 0645 \\
\hline \multirow[t]{2}{*}{12} & 0.33011 & 0.47440 & 0.56544 & 0.69007 & 0.74621 & 1.24675 & 1.33152 & 1.53493 & 1.71827 & 2.18834 \\
\hline & 0.000147 & 0.000079 & 0.000610 & 0.000578 & 80.000225 & 50.002104 & 40.000513 & 30.000574 & 0.000941 & 10.000066 \\
\hline \multirow[t]{2}{*}{13} & 0.36433 & 0.50171 & 0.59290 & 0.71235 & 0.76411 & 1.24658 & 1.32341 & 1.51743 & 1.70589 & 2.07515 \\
\hline & 0.000236 & 0.000486 & 0.000743 & 0.000891 & 10.000459 & 90.001173 & 30.000298 & 0.000447 & 0.000309 & 90.000119 \\
\hline \multirow[t]{2}{*}{14} & 0.37421 & 0.51480 & 0.60460 & 0.72664 & 0.77118 & 1.24092 & 1.30380 & 1.49457 & 1.66006 & 2.02655 \\
\hline & 0.000871 & 0.000432 & 0.000369 & & & & & & & 198 \\
\hline \multirow[t]{2}{*}{15} & 0.38382 & 0.52314 & 0.61516 & 0.72739 & 0.77595 & 1.22814 & 1.28793 & 1.46930 & 1.62245 & 1.96856 \\
\hline & 0.000227 & 0.00364 & 0.000440 & 0.000512 & 20.000809 & 90.000147 & 70.000387 & 70.00113 & 0.000095 & 50.000108 \\
\hline \multirow[t]{2}{*}{20} & 0.45628 & 0.58486 & 0.66182 & 0.76425 & 0.80685 & 1.19424 & 1.25060 & 1.39692 & 1.53788 & 1.81301 \\
\hline & 0.000497 & 0.000257 & 0.000449 & 0.000364 & 40.000431 & 10.000829 & 90.000617 & 70.000767 & 0.000515 & 50.000126 \\
\hline \multirow[t]{2}{*}{25} & 0.50338 & 0.62569 & 0.69054 & 0.78907 & 0.82606 & 1.16700 & 1.21690 & 1.34632 & 1.45022 & 1.68131 \\
\hline & 0.000086 & 0.000376 & 0.000461 & 0.000612 & 20.000069 & 90.000336 & 60.000472 & 20.001640 & 0.000486 & 60.000418 \\
\hline \multirow[t]{2}{*}{30} & 0.54497 & 0.65435 & 0.72136 & 0.80753 & 0.84440 & 1.15279 & 1.19454 & 1.30951 & 1.41009 & 1.60982 \\
\hline & 0.000504 & 0.000072 & 0.000249 & 0.001361 & 10.000648 & 80.000294 & 40.000403 & 30.000114 & 0.000099 & 90.000351 \\
\hline \multirow[t]{2}{*}{50} & 0.62952 & 0.73296 & 0.78559 & 0.85336 & 0.88236 & 1.11777 & 1.14708 & 1.23123 & 1.31118 & 1.45303 \\
\hline & 0.000077 & 0.000469 & 0.000716 & 0.00085 & 80.000767 & 70.000431 & 10.000349 & 0.000228 & 0.000379 & 9.000901 \\
\hline \multirow[t]{2}{*}{100} & 0.73854 & 0.80946 & 0.84783 & 0.89838 & 0.91807 & 1.08507 & 1.10685 & 1.16750 & 1.21870 & 1.31350 \\
\hline & 0.000156 & 0.000237 & 0.000643 & 30.00 & 70.0008 & 70.0003 & 40.0004 & 0.000147 & 0.000 & 20.000419 \\
\hline
\end{tabular}


Table 9 Quantile points of the distribution of $A$ (when $\left|\rho_{y x}\right|=0.80$ )

\begin{tabular}{lllllllllll}
\hline$n$ & $A_{0.01}$ & $A_{0.05}$ & $A_{0.10}$ & $A_{0.20}$ & $A_{0.25}$ & $A_{0.75}$ & $A_{0.80}$ & $A_{0.90}$ & $A_{0.95}$ & $A_{0.99}$ \\
\hline $\mathbf{5}$ & $\mathbf{0 . 1 2 7 6 0}$ & $\mathbf{0 . 2 8 8 4 1}$ & $\mathbf{0 . 3 9 9 7 5}$ & $\mathbf{0 . 5 6 9 4 0}$ & $\mathbf{0 . 6 3 8 7 8}$ & $\mathbf{1 . 4 1 8 0 8}$ & $\mathbf{1 . 5 3 7 9 6}$ & $\mathbf{1 . 9 0 9 3 4}$ & $\mathbf{2 . 3 2 1 1 9}$ & $\mathbf{3 . 2 9 7 8 6}$ \\
& 0.000081 & 0.000553 & 0.000336 & 0.001023 & 0.000559 & 0.000327 & 0.000638 & 0.000443 & 0.0008839 & 0.0001279 \\
$\mathbf{6}$ & $\mathbf{0 . 1 8 8 3 4}$ & $\mathbf{0 . 3 3 3 0 1}$ & $\mathbf{0 . 4 4 6 1 2}$ & $\mathbf{0 . 6 1 0 2 7}$ & $\mathbf{0 . 6 7 6 8 5}$ & $\mathbf{1 . 3 5 8 5 1}$ & $\mathbf{1 . 4 6 9 5 2}$ & $\mathbf{1 . 7 9 9 5 5}$ & $\mathbf{2 . 1 3 5 8 3}$ & $\mathbf{2 . 9 4 2 9 1}$ \\
& 0.000112 & 0.000349 & 0.000243 & 0.000564 & 0.000493 & 0.000587 & 0.000463 & 0.000554 & 0.000199 & 0.000264 \\
$\mathbf{7}$ & $\mathbf{0 . 2 2 7 6 0}$ & $\mathbf{0 . 3 9 0 5 4}$ & $\mathbf{0 . 4 9 7 7 2}$ & $\mathbf{0 . 6 3 3 8 4}$ & $\mathbf{0 . 6 9 9 4 9}$ & $\mathbf{1 . 3 2 0 1 7}$ & $\mathbf{1 . 4 1 3 0 3}$ & $\mathbf{1 . 6 8 6 8 3}$ & $\mathbf{1 . 9 4 8 8 8}$ & $\mathbf{2 . 5 9 5 1 9}$ \\
& 0.000664 & 0.000069 & 0.000333 & 0.000443 & 0.000980 & 0.001183 & 0.000337 & 0.000873 & 0.000492 & 0.000146 \\
$\mathbf{8}$ & $\mathbf{0 . 2 6 2 8 2}$ & $\mathbf{0 . 4 2 4 2 5}$ & $\mathbf{0 . 5 2 5 6 2}$ & $\mathbf{0 . 6 6 9 9 1}$ & $\mathbf{0 . 7 2 5 7 3}$ & $\mathbf{1 . 2 9 2 9 3}$ & $\mathbf{1 . 3 7 9 5 6}$ & $\mathbf{1 . 6 2 5 7 0}$ & $\mathbf{1 . 8 5 2 2 0}$ & $\mathbf{2 . 3 5 7 2 3}$
\end{tabular}
$\begin{array}{llllllllllllll}0.000813 & 0.000546 & 0.000237 & 0.000615 & 0.000543 & 0.000329 & 0.000443 & 0.0005060 .000447 & 0.000118\end{array}$

$\begin{array}{lllllllllll}9 & 0.30571 & 0.46255 & 0.55397 & 0.69242 & 0.74858 & 1.28245 & 1.36366 & 1.57725 & 1.78672 & 2.24067\end{array}$ $\begin{array}{lllllllllll}0.000440 & 0.000728 & 0.000981 & 0.000381 & 0.000238 & 0.000119 & 0.000441 & 0.000665 & 0.000873 & 0.000243\end{array}$

$\begin{array}{lllllllllll}10 & 0.32731 & 0.48501 & 0.57467 & 0.70030 & 0.75381 & 1.25290 & 1.32744 & 1.52305 & 1.70744 & 2.17709\end{array}$ $\begin{array}{lllllllllll}0.000776 & 0.000321 & 0.000449 & 0.000834 & 0.001023 & 0.000409 & 0.000734 & 0.000493 & 0.000654 & 0.000555\end{array}$

$\begin{array}{lllllllllll}11 & 0.35820 & 0.50426 & 0.59668 & 0.71791 & 0.76907 & 1.23761 & 1.30845 & 1.50528 & 1.67926 & 2.10165\end{array}$ $\begin{array}{lllllllllll}0.000077 & 0.000444 & 0.000332 & 0.000965 & 0.000853 & 0.000678 & 0.000195 & 0.001132 & 0.000765 & 0.000065\end{array}$

$\begin{array}{llllllllllll}12 & 0.36747 & 0.51731 & 0.60870 & 0.72647 & 0.77378 & 1.23216 & 1.29525 & 1.47356 & 1.64414 & 1.97034\end{array}$ $\begin{array}{lllllllllllll}0.000617 & 0.000447 & 0.000331 & 0.000219 & 0.000664 & 0.000987 & 0.000888 & 0.000067 & 0.000553 & 0.000446\end{array}$

$\begin{array}{lllllllllll}13 & 0.39388 & 0.53966 & 0.62847 & 0.73960 & 0.78566 & 1.21811 & 1.28135 & 1.45056 & 1.61294 & 1.96986\end{array}$ $\begin{array}{llllllllllll}0.000887 & 0.000616 & 0.00209 & 0.000336 & 0.000489 & 0.000721 & 0.000883 & 0.000381 & 0.000459 & 0.000228\end{array}$

$\begin{array}{lllllllllll}14 & 0.41966 & 0.55855 & 0.64399 & 0.75382 & 0.79864 & 1.21084 & 1.26531 & 1.43116 & 1.58240 & 1.90339\end{array}$ $\begin{array}{llllllllll}0.000210 & 0.000529 & 0.000873 & 0.000919 & 0.000889 & 0.000694 & 0.000087 & 0.001123 & 0.000556 & 0.000129\end{array}$

$\begin{array}{lllllllllll}15 & 0.42497 & 0.57242 & 0.65493 & 0.76315 & 0.80708 & 1.20153 & 1.26120 & 1.42446 & 1.57170 & 1.89125\end{array}$ $\begin{array}{llllllllll}0.000819 & 0.000239 & 0.000132 & 0.000089 & 0.001143 & 0.000553 & 0.000646 & 0.000236 & 0.000476 & 0.000369\end{array}$

$\begin{array}{lllllllllll}20 & 0.50252 & 0.63058 & 0.70189 & 0.79165 & 0.83098 & 1.17480 & 1.22160 & 1.34186 & 1.46084 & 1.68477\end{array}$ $\begin{array}{llllllllllllll}0.000568 & 0.000719 & 0.001006 & 0.000090 & 0.000687 & 0.000813 & 0.000147 & 0.000623 & 0.000049 & 0.000238\end{array}$

$\begin{array}{lllllllllll}25 & 0.53893 & 0.65786 & 0.72923 & 0.81468 & 0.84746 & 1.14945 & 1.19313 & 1.29974 & 1.39123 & 1.58336\end{array}$ $\begin{array}{lllllllllll}0.000777 & 0.000159 & 0.000398 & 0.000858 & 0.000903 & 0.001225 & 0.000714 & 0.000342 & 0.000369 & 0.000200\end{array}$

$\begin{array}{lllllllllll}30 & 0.58633 & 0.69327 & 0.75731 & 0.83688 & 0.86895 & 1.13997 & 1.17633 & 1.28460 & 1.36762 & 1.54026\end{array}$

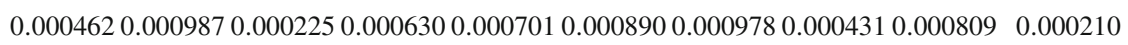

$\begin{array}{lllllllllll}50 & 0.67413 & 0.76400 & 0.81535 & 0.87490 & 0.89816 & 1.10330 & 1.13112 & 1.20826 & 1.27396 & 1.40340\end{array}$ $\begin{array}{llllllllll}0.000413 & 0.000654 & 0.002107 & 0.000568 & 0.000612 & 0.000830 & 0.000912 & 0.000887 & 0.000923 & 0.000102\end{array}$

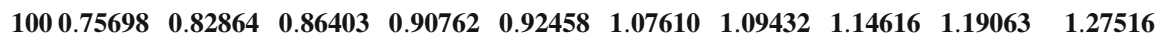
$\begin{array}{llllllllllllllll}0.000236 & 0.000458 & 0.000248 & 0.003698 & 0.001097 & 0.000489 & 0.000721 & 0.000111 & 0.000874 & 0.000125\end{array}$ 
Table 10 Quantile points of the distribution of $A$ (when $\left|\rho_{y x}\right|=0.90$ )

\begin{tabular}{lllllllllll}
\hline$n$ & $A_{0.01}$ & $A_{0.05}$ & $A_{0.10}$ & $A_{0.20}$ & $A_{0.25}$ & $A_{0.75}$ & $A_{0.80}$ & $A_{0.90}$ & $A_{0.95}$ & $A_{0.99}$ \\
\hline $\mathbf{5}$ & $\mathbf{0 . 1 9 0 3 1}$ & $\mathbf{0 . 3 7 9 8 1}$ & $\mathbf{0 . 4 9 4 1 0}$ & $\mathbf{0 . 6 5 4 9 2}$ & $\mathbf{0 . 7 1 9 6 3}$ & $\mathbf{1 . 3 2 6 3 0}$ & $\mathbf{1 . 4 2 0 6 8}$ & $\mathbf{1 . 7 1 9 6 8}$ & $\mathbf{2 . 0 5 6 1 6}$ & $\mathbf{2 . 9 9 2 7 0}$ \\
& 0.000140 & 0.000613 & 0.000085 & 0.000467 & 0.000349 & 0.000278 & 0.000821 & 0.000467 & 0.000594 & 0.000746 \\
$\mathbf{6}$ & $\mathbf{0 . 2 6 3 1 4}$ & $\mathbf{0 . 4 4 8 8 0}$ & $\mathbf{0 . 5 5 2 8 1}$ & $\mathbf{0 . 6 9 4 4 2}$ & $\mathbf{0 . 7 4 9 5 5}$ & $\mathbf{1 . 2 7 5 0 0}$ & $\mathbf{1 . 3 5 6 1 8}$ & $\mathbf{1 . 6 0 9 6 4}$ & $\mathbf{1 . 8 3 3 8 9}$ & $\mathbf{2 . 4 9 8 5 5}$ \\
& 0.000216 & 0.000649 & 0.000526 & 0.000348 & 0.000456 & 0.000627 & 0.000919 & 0.000278 & 0.000446 & 0.000290 \\
$\mathbf{7}$ & $\mathbf{0 . 3 0 9 1 8}$ & $\mathbf{0 . 4 8 4 6 7}$ & $\mathbf{0 . 5 8 5 6 8}$ & $\mathbf{0 . 7 2 6 1 2}$ & $\mathbf{0 . 7 7 6 6 0}$ & $\mathbf{1 . 2 5 4 3 8}$ & $\mathbf{1 . 3 2 3 3 1}$ & $\mathbf{1 . 5 3 5 9 3}$ & $\mathbf{1 . 7 3 6 4 0}$ & $\mathbf{2 . 3 0 7 0 5}$ \\
& 0.000336 & 0.000673 & 0.000246 & 0.000081 & 0.000097 & 0.000592 & 0.000249 & 0.000462 & 0.000074 & 0.000056
\end{tabular}

$\begin{array}{lllllllllll}8 & 0.35150 & 0.51813 & 0.61600 & 0.73896 & 0.78776 & 1.22601 & 1.29113 & 1.47426 & 1.66615 & 2.10205\end{array}$ $\begin{array}{llllllllll}0.000552 & 0.000629 & 0.000527 & 0.000479 & 0.000697 & 0.000227 & 0.001462 & 0.000376 & 0.000916 & 0.000179\end{array}$

$\begin{array}{lllllllllll}9 & 0.39752 & 0.55700 & 0.64318 & 0.75811 & 0.80072 & 1.22242 & 1.28047 & 1.44535 & 1.59290 & 1.96710\end{array}$ 0.0003180 .0006650 .0005870 .0001920 .0000840 .0004530 .0002160 .0004710 .0006150 .000334

$\begin{array}{lllllllllll}10 & 0.43652 & 0.58053 & 0.66296 & 0.77073 & 0.81538 & 1.19784 & 1.25482 & 1.41366 & 1.55279 & 1.87735\end{array}$ $\begin{array}{llllllllllllllll}0.000292 & 0.000565 & 0.000413 & 0.000946 & 0.000729 & 0.000183 & 0.000078 & 0.000824 & 0.000561 & 0.000091\end{array}$

$\begin{array}{lllllllllll}11 & 0.45717 & 0.59920 & 0.67945 & 0.78104 & 0.82524 & 1.19087 & 1.24014 & 1.38008 & 1.51322 & 1.82994\end{array}$ 0.0004680 .0004090 .0002730 .0006940 .0005920 .0007740 .0008160 .0000870 .0004120 .000345

$\begin{array}{lllllllllll}12 & 0.48045 & 0.61447 & 0.70043 & 0.80068 & 0.83242 & 1.18253 & 1.22862 & 1.36613 & 1.48909 & 1.79328\end{array}$ $\begin{array}{llllllllll}0.000447 & 0.000613 & 0.000276 & 0.000489 & 0.000625 & 0.000714 & 0.000885 & 0.000215 & 0.000645 & 0.000089\end{array}$

$\begin{array}{lllllllllll}13 & 0.48976 & 0.62854 & 0.70669 & 0.80201 & 0.83719 & 1.16927 & 1.21266 & 1.33232 & 1.44752 & 1.73246\end{array}$ $\begin{array}{lllllllllll}0.000236 & 0.000378 & 0.0005730 .000824 & 0.0004420 .000334 & 0.000496 & 0.0005470 .000771 & 0.000464\end{array}$

$\begin{array}{lllllllllll}14 & 0.50880 & 0.63869 & 0.70883 & 0.80547 & 0.84072 & 1.16534 & 1.20953 & 1.32777 & 1.43774 & 1.67538\end{array}$ $\begin{array}{lllllllllllllll}0.000417 & 0.000168 & 0.000211 & 0.000467 & 0.000555 & 0.000743 & 0.000698 & 0.000549 & 0.000628 & 0.000362\end{array}$

$\begin{array}{lllllllllll}15 & 0.52828 & 0.65868 & 0.72708 & 0.81693 & 0.84924 & 1.15741 & 1.19817 & 1.31441 & 1.42044 & 1.65283\end{array}$ $\begin{array}{lllllllllllllll}0.000064 & 0.000264 & 0.000728 & 0.000341 & 0.000673 & 0.000483 & 0.000607 & 0.000894 & 0.000761 & 0.000259\end{array}$

$\begin{array}{lllllllllll}20 & 0.59635 & 0.70751 & 0.76927 & 0.84372 & 0.87183 & 1.13026 & 1.16700 & 1.26102 & 1.34918 & 1.53386\end{array}$ $\begin{array}{llllllllllll}0.000164 & 0.000647 & 0.000275 & 0.000349 & 0.000543 & 0.000673 & 0.000916 & 0.000783 & 0.000662 & 0.000805\end{array}$

$\begin{array}{lllllllllll}25 & 0.64662 & 0.73617 & 0.79215 & 0.86170 & 0.88928 & 1.11688 & 1.14531 & 1.23331 & 1.30798 & 1.46080\end{array}$ $\begin{array}{lllllllllllll}0.000111 & 0.000267 & 0.000790 & 0.000463 & 0.000583 & 0.000918 & 0.000664 & 0.000785 & 0.000553 & 0.000449\end{array}$

$\begin{array}{lllllllllll}30 & 0.65662 & 0.76113 & 0.81080 & 0.87393 & 0.89996 & 1.10272 & 1.13057 & 1.20550 & 1.26921 & 1.39693\end{array}$ $\begin{array}{lllllllllllll}0.000330 & 0.000453 & 0.000576 & 0.000918 & 0.000557 & 0.000246 & 0.000776 & 0.000076 & 0.000162 & 0.000238\end{array}$

$\begin{array}{lllllllllll}50 & 0.73552 & 0.81359 & 0.85080 & 0.90160 & 0.91985 & 1.08025 & 1.10067 & 1.15688 & 1.20589 & 1.29695\end{array}$ $\begin{array}{llllllllllllllll}0.000444 & 0.000349 & 0.000194 & 0.000853 & 0.000627 & 0.000435 & 0.000864 & 0.000761 & 0.000565 & 0.000068\end{array}$ $\begin{array}{lllllllllll}100 & 0.81336 & 0.86827 & 0.89651 & 0.93144 & 0.94546 & 1.05754 & 1.07180 & 1.11188 & 1.14567 & 1.20903\end{array}$ $\begin{array}{llllllllll}0.000301 & 0.000462 & 0.000879 & 0.000276 & 0.000764 & 0.000345 & 0.000682 & 0.000943 & 0.000073 & 0.000143\end{array}$ 
Table 11 Quantile points of the distribution of $A$ (when $\left.\left|\rho_{y x}\right|=0.99\right)$

\begin{tabular}{lllllllllll}
\hline$n$ & $A_{0.01}$ & $A_{0.05}$ & $A_{0.10}$ & $A_{0.20}$ & $A_{0.25}$ & $A_{0.75}$ & $A_{0.80}$ & $A_{0.90}$ & $A_{0.95}$ & $A_{0.99}$ \\
\hline $\mathbf{5}$ & $\mathbf{0 . 5 6 3 5 0}$ & $\mathbf{0 . 7 2 6 7 4}$ & $\mathbf{0 . 8 0 0 1 0}$ & $\mathbf{0 . 8 7 3 1 0}$ & $\mathbf{0 . 8 9 9 5 3}$ & $\mathbf{1 . 1 0 7 8 0}$ & $\mathbf{1 . 1 3 9 0 8}$ & $\mathbf{1 . 2 3 1 1 8}$ & $\mathbf{1 . 3 3 1 7 9}$ & $\mathbf{1 . 6 5 2 0 0}$ \\
& 0.000080 & 0.000094 & 0.000157 & 0.000346 & 0.000662 & 0.000580 & 0.000328 & 0.000463 & 0.000846 & 0.000393 \\
$\mathbf{6}$ & $\mathbf{0 . 6 4 2 2 7}$ & $\mathbf{0 . 7 7 0 0 8}$ & $\mathbf{0 . 8 2 8 7 3}$ & $\mathbf{0 . 8 8 9 0 5}$ & $\mathbf{0 . 9 1 0 6 2}$ & $\mathbf{1 . 0 9 5 7 3}$ & $\mathbf{1 . 1 2 0 9 9}$ & $\mathbf{1 . 1 9 5 5 9}$ & $\mathbf{1 . 2 6 8 1 4}$ & $\mathbf{1 . 4 9 9 1 1}$ \\
& 0.000680 & 0.000293 & 0.000430 & 0.000367 & 0.000591 & 0.000440 & 0.000442 & 0.000407 & 0.000673 & 0.000219 \\
$\mathbf{7}$ & $\mathbf{0 . 6 9 0 4 6}$ & $\mathbf{0 . 7 9 6 2 9}$ & $\mathbf{0 . 8 4 2 5 4}$ & $\mathbf{0 . 8 9 7 7 4}$ & $\mathbf{0 . 9 1 7 7 4}$ & $\mathbf{1 . 0 8 6 8 2}$ & $\mathbf{1 . 1 0 8 6 8}$ & $\mathbf{1 . 1 7 5 1 7}$ & $\mathbf{1 . 2 3 9 3 5}$ & $\mathbf{1 . 4 3 2 7 6}$ \\
& 0.000413 & 0.000529 & 0.000225 & 0.000919 & 0.000612 & 0.000553 & 0.000883 & 0.000431 & 0.000459 & 0.000210 \\
$\mathbf{8}$ & $\mathbf{0 . 7 2 5 5 3}$ & $\mathbf{0 . 8 1 4 8 1}$ & $\mathbf{0 . 8 5 8 6 0}$ & $\mathbf{0 . 9 0 7 6 0}$ & $\mathbf{0 . 9 2 5 4 8}$ & $\mathbf{1 . 0 7 6 1 7}$ & $\mathbf{1 . 0 9 6 3 3}$ & $\mathbf{1 . 1 5 3 8 9}$ & $\mathbf{1 . 2 1 2 0 9}$ & $\mathbf{1 . 3 5 5 1 1}$
\end{tabular}

$\begin{array}{lllllllllll}8 & 0.72553 & 0.81481 & 0.85860 & 0.90760 & 0.92548 & 1.07617 & 1.09633 & 1.15389 & 1.21209 & 1.35511\end{array}$ 0.0004280 .0006720 .0008160 .0001790 .0007620 .00008640 .0009630 .0004260 .0004920 .000195

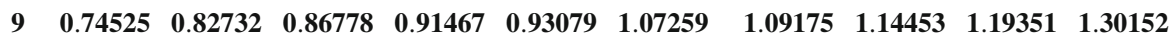
0.0000780 .0001170 .0006450 .0005310 .0002760 .0005820 .0009190 .0007260 .0005730 .000372

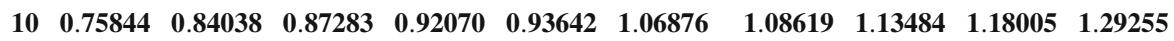

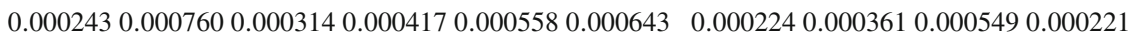

$\begin{array}{lllllllllll}11 & 0.77049 & 0.84236 & 0.87868 & 0.92220 & 0.93827 & 1.06267 & 1.07894 & 1.12522 & 1.16809 & 1.25977\end{array}$

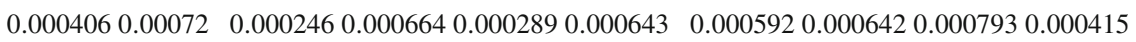

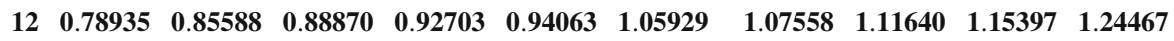
0.0000640 .0001830 .0006750 .0006420 .0005560 .0004620 .0001900 .0008670 .0004730 .000276

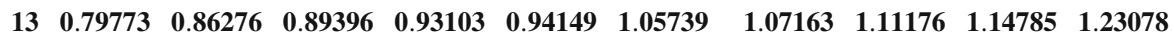
$\begin{array}{lllllll}0.000493 & 0.000671 & 0.0004630 .0005120 .0007930 .000474 & 0.0007760 .0006490 .000379 & 0.000226\end{array}$

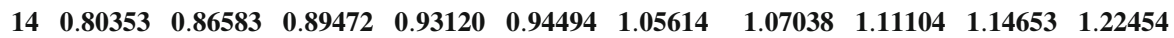
$\begin{array}{lllllll}0.000713 & 0.000446 & 0.000573 & 0.000876 & 0.0004130 .000997 & 0.000408 & 0.0006730 .0005760 .000245\end{array}$

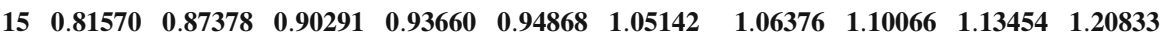
$\begin{array}{lllllllll}0.000346 & 0.000442 & 0.000576 & 0.000461 & 0.000911 & 0.000567 & 0.000605 & 0.0007770 .000294 & 0.000090\end{array}$

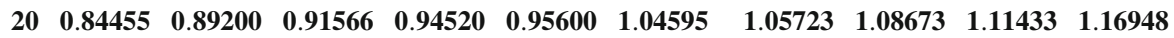

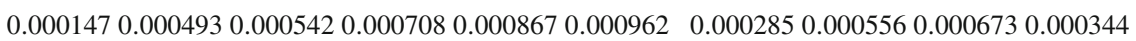

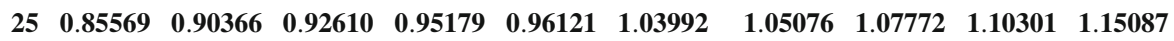

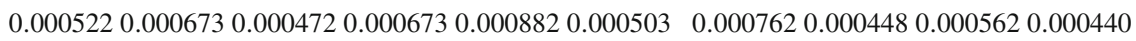

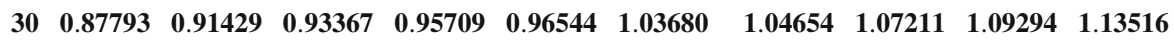
$0.0004150 .0006490 .0007510 .0009060 .0006830 .000286 \quad 0.0007940 .0006640 .0000740 .000675$

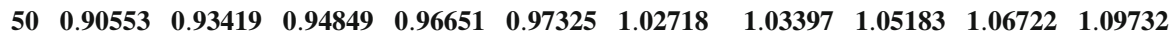
0.0002760 .0005270 .0006670 .0007500 .0008830 .0006490 .0002460 .0000830 .0001280 .000248

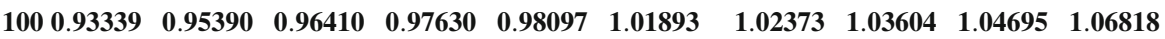

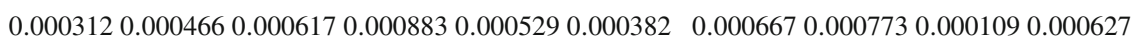




\section{References}

Acosta-Mejia CAJr, Pignatiello JJ, Rao BV (1999) A comparison of control charting procedures for monitoring process dispersion. IIE Trans 31:569-579

Adhvaryu A (1975) Combination of some estimators using supplementary information. J Ind Soc Agric Stat 27:37-50

Albers W, Kallenberg WCM (2006) Self-adapting control charts. Stat Neerlandica 60:292-308

Alt FB (1985) Multivariate quality control. In: Johnson NL, Kotz S (eds) Encyclopedia of statistical sciences, vol 6. Wiley, New York

Alwan LC (2000) Statistical process analysis. McGraw-Hill International Edition, New York

Battaglia GJ (1993) Regression-based statistical process control. AMP J Technol 3:38-45

Chen FL, Huang HJ (2005) A Synthetic control chart for monitoring process dispersion with sample standard deviation. Comput Indust Eng 49(2):221-240

Chun YH (2000) A Ranked-based statistical control chart for the process mean. In: Proceedings of the 11th annual conference of the production and the operations management society, April 1-4, 2000, San Antonio

Ding Y, Zhou S, Chen Y (2005) A Comparison of process variation estimators for in-process dimensional measurements and control. J Dyn Syst Meas Control 127:69-79

Duncan AJ (1951) Operating characteristics of R charts. Indust Qual Control 7:40-41

Farnum NR (1994) Statistical quality control and improvement. Duxbury, Belmont

Garcia MR, Cebrian AA (1996) Repeated substitution method: the ratio estimator for the population variance. Metrika 43:101-105

Gonzalez IM, Viles E (2000) Semi-economic design of $\bar{X}$-control charts assuming gamma distribution. Econ Qual Control 15:109-118

Gonzalez IM, Viles E (2001) Design of $R$ control chart assuming a gamma distribution. Econ Qual Control 16(2):199-204

Hawkins DM (1991) Multivariate quality control based on regression-adjusted variables. Technometrics 33(1):61-75

Hawkins DM (1993) Regression adjustment for variables in multivariate quality control. J Qual Technol 25(3):170-182

He D, Grigoryan A (2006) Joint statistical design of double sampling $X$ and S charts. Euro J Oper Res 168(1):122-142

Hillier FS (1969) $\bar{X}$ and R chart control limits based on a small number of subgroups. J Qual Technol $1: 17-26$

Isaki CT (1983) Variance estimation using auxiliary information. J Am Stat Assoc 78:117-123

Jones LA, Champ CW, Rigdon SE (2004) The run length distribution of the CUSUM with estimated parameters. J Qual Technol 36(1):95-108

Knoth S (2005) Fast initial response features for EWMA control charts. Stat Papers 46(1):47-64

Magnus JR (2002) Estimation of the mean of a univariate normal distribution with known variance. Economet J 5:225-236

Mandel BJ (1969) The regression control chart. J Qual Technol 1:1-9

Muhammad F, Riaz M (2006) Probability weighted moments approach to quality control charts. Econ Qual Control 21(2):165-174

Muttlak HA, Al-Sabah W (2001) Statistical quality control using ranked set sampling. Technical Report No. FT/2000-15, Department of Mathematical Sciences, KFUPM, November (2001)

Naik VD, Gupta PC (1991) A general class of estimators for estimating population mean using auxiliary information. Metrika 38:11-17

Nelson LS (1984) The Shewhart control chart-tests for special causes. J Qual Technol 21:287-289

Nelson PR (1985) Power curves for the analysis of means. Technometrics 27:65-73

Olkin I (1958) Multivariate ratio estimation for finite population. Biometrika 45:154-165

Pappanastos EA, Adams BM (1996) Alternative design of Hodges-Lehmann control chart. J Qual Technol 28(2):213-223

Pearson ES (1932) The percentage limits for the distribution of range in samples from a normal population. Biometrika 18:404-417

Quesenberry CP (1997) SPC methods for quality improvement. Wiley, New York

Ramalhoto MF, Morais M (1999) Shewhart control charts for the scale parameter of a Weibull control variable with fixed and variable sampling intervals. J Appl Stat 26(1):129-160 
Rao PSRA, Mudholkar GS (1967) Generalized multivariate estimator for the mean of finite population. J Am Stat Assoc 62:1009-1012

Reynolds MR Jr, Arnold JC (2001) EWMA control charts with variable sample sizes and variable sampling intervals. IIE Trans 33(6):511-530

Riaz M (2008a) Monitoring process variability using auxiliary information. Comput Stat 23(2):253-276

Riaz M (2008b) Monitoring process mean level using auxiliary information. Statistica Neerlandica, To appear, This article is available as OnlineEarly at the website http://www.blackwellpublishing.com/ journal.asp?ref=00390-402\\&site=1

Riaz M, Saghir A (2007) Monitoring process variability using Gini’s mean difference. Qual Technol Quant Manage 4(4):439-454

Ross SM (1990) A course in simulations. Macmillan Pub. Co, New York

Scheffe H (1949) Operating characteristics of average and range charts. Indust Qual Control 5:13-18

Shewhart W (1931) Economic control of quality manufactured product, D. Van Nostrand, New York; reprinted by the American Society for Quality Control in 1980, Milwauker

Shewhart W (1939) Statistical method from the viewpoint of Quality Control, Graduate School Department of Agriculture, Washington, D. C., reprinted by Dover publication in 1986, Mineola

Shu L, Tsung F, Tsui KL (2005) Effects of estimation errors on cause-selecting charts. IIE Trans 37:559-567

Singh R, Mangat NS (1996) Elements of survey sampling. Kluwer, Dordrecht

Singh HP, Upadhyaya LN, Chandra P (2004) A general family of estimators for estimating population mean using two auxiliary variables in two phase sampling. Stat Transit 6:1055-1077

Tuprah K, Ncube M (1987) A comparison of dispersion quality control charts. Sequent Anal 6:155-163

Wade MR, Woodall WH (1993) A review and analysis of cause-selecting control charts. J Qual Technol 25(3):161-169

Wheeler DJ (1995) Advanced topics in statistical process control-the power of Shewhart's charts. SPC Press, Knoxville

Yang CH, Hiller FS (1970) Mean and variance control chart limits based on a small number of subgroup. J Qual Technol 2:9-16

Yu PLH, Lam K (1997) Regression estimator in ranked set sampling. Biometrics 53(3):1070-1080

Zhang GX (1984) A new type of control charts and a theory of diagnosis with control charts. World quality congress transactions. American Society for Quality Control, London, pp 175-185

Zhang GX (1985) Cause-selecting control charts-A new type of quality control charts. QR J 12:221-225 